\title{
1 Metabolic breakdown of non-small cell lung cancers by mitochondrial 2 HSPD1 targeting
}

3

5

6

Beatrice Parma ${ }^{1}$, Vignesh Ramesh¹, Paradesi Naidu Gollavilli', Aarif Siddiqui², Luisa Pinna ${ }^{1}$, Annemarie Schwab루, Sabine Marschall ${ }^{1}$, Shuman Zhang ${ }^{3}$, Christian Pilarsky ${ }^{3}$, Francesca Napoli ${ }^{4}$, Marco Volante ${ }^{4}$, Sophia Urbanczyk ${ }^{5}$, Dirk Mielenz ${ }^{5}$, Henrik Daa Schrøder ${ }^{6}$, Marc Stemmler ${ }^{7}$, Heiko Wurdak $^{8^{\star}}$ and Paolo Ceppi ${ }^{1,2^{*}}$

1 Interdisciplinary Center for Clinical Research (IZKF), Friedrich-Alexander University of ErlangenNuremberg, Erlangen, Germany

${ }^{2}$ Department of Biochemistry and Molecular Biology, University of Southern Denmark, Odense, Denmark ${ }^{3}$ Department of Surgery, Friedrich-Alexander University of Erlangen- Nuremberg (FAU) and University Hospital of Erlangen, Erlangen, Germany

${ }^{4}$ Department of Oncology at San Luigi Hospital, University of Turin, Orbassano, Turin, Italy ${ }^{5}$ Department of Molecular Immunology, Friedrich-Alexander University of Erlangen-Nuremberg, Erlangen, Germany

${ }^{6}$ Department of Pathology, Odense University Hospital, Odense, Denmark

${ }^{7}$ Department of Experimental Medicine-I, Friedrich-Alexander University of Erlangen-Nuremberg, Erlangen, Germany

${ }^{8}$ Stem Cell and Brain Tumour Group, School of Medicine, University of Leeds, Leeds LS2 9JT, UK

* To whom correspondence should be addressed.

Dr. Paolo Ceppi, Dept. of Biochemistry and Molecular Biology, University of Southern Denmark, Campusvej 55, 5230 Odense M, Denmark Tel: +45 655048 80; Email: pceppi@bmb.sdu.dk;

Dr. Heiko Wurdak, School of Medicine, University of Leeds, Leeds LS2 9JT, UK. Email:

h.wurdak@leeds.ac.uk

Running title: HSPD1 in non-small cell lung cancer

Keywords: non-small cell lung cancer, metabolism, HSPD1, targeting, KHS101 
bioRxiv preprint doi: https://doi org/10.1101/2021.03.09.434573; this version posted March 9, 2021. The copyright holder for this preprint (which was not certified by peer review) is the author/funder, who has granted bioRxiv a license to display the preprint in perpetuity. It is made available under aCC-BY-NC-ND 4.0 International license.

29 Funding: this work was supported by the Interdisciplinary Center for Clinical Research of the University

30 of Erlangen-Nuremberg (PC) and the German Research Foundation grant DFG-CE-281/5-1 (PC; BP). CP

31 is supported by the European Research Council (MSCA-ITN-ETN PRECODE 861196).

32 The Authors declare no potential conflicts of interest.

33

34 Words: 5,000; main figures: 7; supplementary figures: 8; supplementary tables: 8

35

36

37

38

39

40

41

42

43

44

45

46

47

48

49

50

51

52

53

54

55 


\section{ABSTRACT}

57 The identification of novel targets is of paramount importance to develop more effective drugs and improve the treatment of non-small cell lung cancer (NSCLC), the leading cause of cancer-related deaths worldwide.

59 Since cells alter their metabolic rewiring during tumorigenesis and along cancer progression, targeting key 60 metabolic players and metabolism-associated proteins represents a valuable approach with a high

61 therapeutic potential. Metabolic fitness relies on the functionality of heat shock proteins (HSPs), molecular 62 chaperones that facilitate the correct folding of metabolism enzymes and their assembly in macromolecular 63 structures. Here, we show HSPD1 (HSP60) as a survival gene ubiquitously expressed in NSCLC and 64 associated with poor patients' prognosis. HSPD1 knockdown or its chemical disruption by the small 65 molecule KHS101 induces a drastic breakdown of oxidative phosphorylation, and suppresses cell proliferation both in vitro and in vivo. By combining drug profiling with transcriptomics and through a wholegenome CRISPR/Cas9 screen, we demonstrate that HSPD1-targeted anti-cancer effects are dependent on OXPHOS and validated molecular determinants of KHS101 sensitivity, in particular, the creatinetransporter SLC6A8 and the subunit of the cytochrome c oxidase complex COX5B. These results highlight mitochondrial metabolism as an attractive target and HSPD1 as a potential theranostic marker for developing therapies to combat NCSLC.

Significance: HSPD1 elimination or disruption interferes with NSCLC metabolic activity causing a strong 


\section{INTRODUCTION}

Lung cancer is the most commonly diagnosed cancer worldwide and the main cause of cancer-related death in both men and women (1). Non-small cell lung cancer (NSCLC) is lung most frequent type occurring in about $85 \%$ of cases (2), mainly presenting with an adenocarcinoma (LUAD) or squamous cell lung cancer (SqCC) histology (3). The standard of care for NSCLC has considerably changed in the last decade with the introduction of target therapies and immunotherapies. These, in synergy with chemo/radiotherapy, allowed to improve the clinical outcome of a fraction of NSCLC patients, in some cases providing a durable disease stabilization (4). Nevertheless, relapse and occurrence of treatment-resistant phenotypes are still very common, contributing to the current suboptimal scenario of 60 to $70 \%$ overall survival for early-stage and between 0 to $10 \%$ for patients carrying the advanced disease (5). This unsatisfactory picture strongly reinforces the need for developing new drugs targeting other fundamental lethal properties of LC cells. It has long been established that cancer cells alter their metabolism to sustain their increased energetic demands and fuel the malignant phenotype (6). In contrast, or rather as an expansion of the so-called "Warburg effect", it is now clear that cancers not only depend on glycolysis for their growth, but also rely on mitochondrial respiration (7), enabling a hybrid or "plastic" behavior in which an opportunistic energetic adaptability determines or facilitate survival and aggressiveness (8). However, the metabolic alterations frequently found in tumor cells could be turned into therapeutic opportunities, as the newly acquired cancerspecific vulnerabilities or dependencies have been found to represent, in some cases, excellent drug targets $(9,10)$. Recent pivotal studies have shown the power of this approach to induce a significant tumor growth arrest (11-13).

Many key cellular metabolic processes are dependent on the functionality of heat shock proteins (HSPs) (14). HSPs are highly conserved ATP-dependent molecular chaperons mainly involved in maintaining the correct protein structure, for instance avoiding mis-folding or aggregation and protecting cell integrity under stressful conditions (15). High levels of HSPs have been found in different cancer cells, where they sustain higher metabolic demand and correct misfolded oncoproteins (16). The mitochondrial heat shock protein family D member 1 (HSPD1), also called HSP60, belongs to this family (17) and together with the cochaperonin HSP10 plays an essential role in mitochondrial-imported proteins folding or refolding under mitochondrial stress (18). HSPD1 is involved in several diseases such as neurodegenerative disorders or cardiovascular diseases (19). In addition, HSPD1 carries a central role in cancer development, with either pro-survival or pro-apoptotic functions reported in different tumor types (20). In NSCLC, HSPD1 It has been proposed as a biomarker, but little is known about its role or the effects of its suppression $(21,22)$. Here, we investigated the tumor-promoting role of HSPD1 and explored if its targeting could interfere with the malignant metabolic mechanisms underlying NSCLC. Our results revealed HSPD1 as a ubiquitous lung cancer dependency gene, which maintains the metabolic fitness and promotes growth/survival, thus highlighting it as an attractive therapeutic target for NSCLC. 


\section{METHODS}

\section{Cell culture and chemicals}

126 All cell lines were cultured in media supplemented with 10\% FBS, 1\% Pen/Strep and 1\% L-Glutamine (all 127 from Sigma) at $37{ }^{\circ} \mathrm{C}$ and $5 \% \mathrm{CO}_{2}$ in a humidified incubator. $\mathrm{H} 460, \mathrm{H} 1299$, H520, SK-MES-1 and Calu-1 128 (from ATCC) were cultured in RMPI-1640 (Sigma). H23 and H838 (both from ATCC) cells were cultured in RMPI-1640, supplemented with $1 \mathrm{mM}$ sodium pyruvate (Gibco). A549 (ATCC), BEN (DSMZ), murine Lewis lung carcinoma cell line LL2, Ladi2.1 and Ladi3.1 cells (derived from p53fl/fl-LSL KRASG12D/+ mouse NSCLC model) were cultured in DMEM (Sigma). Human cells were STR-profiled, used between passages

1323 and 15, examined for mycoplasma regularly (detection kit from Invivogen). A549-Cas9 cell line was 133 generated by lentiviral transduction with lentiCas9-Blast (Addgene \#52962) and selection with $100 \mu \mathrm{g} / \mathrm{mL}$ 134 of blasticidin (Sigma) for 3 days. KHS101 hydrochloride (4888) was purchased from Tocris; cisplatin (CAS 135 15663-27-1), Z-VAD-FKM (CAS 187389-52-2) and 2-Deoxy-D-Glucose (sc-202010) were purchased from 136 Santa Cruz Biotechnology; Adenosine 5'-triphosphate (ATP) disodium salt hydrate (A1852-1VL), 137 Necrostatin-1 (N9037-10NMG), Ferrostatin-1 (SML0583-5MG) and 1-Fluoro-2,4-dinitrobenzene (DNFB, D1529) were purchased from Sigma. HB072 was obtained as previously shown (23).

\section{Proliferation assay and in vitro drug treatment}

For in vitro drug treatment, cells were plated in a 96-well plate in low density (5-10\% initial confluence) and incubated overnight. On the next day, cells were treated either with vehicle or with the drugs. Plates were loaded in IncuCyte-Zoom (Essen Bioscience) and scanned every 2-4 hours. For each scan, phase contrast image was acquired from every well and was analyzed by IncuCyte Zoom software. $\mathrm{IC}_{50}$ value was calculated after 72 hours of treatment as expression of confluency percentage of treated cells normalized to vehicle control (100\% confluency) and using Graphpad (nonlinear regression curve fitting model) to obtain the value. Proliferation assay was performed as described in (24). Growth curves were analyzed with 2-way ANOVA test.

\section{Cytotoxicity death assay}

151 For cytotoxicity death assay, cells were seeded in 96-well plates in low density (5,000 cells/well) and 152 incubated overnight. 1000X Cytotox Green Reagent or Caspase 3/7 Green Apoptosis Assay Reagent 153 (Essen Bioscience) was diluted in medium and working dilutions of the drug were prepared in Cytotox 154 Green or Caspase3/7 Green supplemented media. After treatment, plates were loaded in IncuCyte Zoom 155 and images were acquired in real-time for phase to quantify growth. Activity of green reagent was 156 simultaneously acquired at the green channel to quantify death. IncuCyte Zoom software was used for the 157 analysis and data export

\section{Extracellular flux assays}


Basal oxygen consumption rate (OCR) and basal extracellular acidification rate (ECAR) measurements were determined using the XFe96 Extracellular Flux Analyzer (Seahorse Bioscience/Agilent Technologies). Cells were seeded in specialized culture microplates at a density of 10,000-20,000 cells/well and prepared as describe in (25). For Mito Stress Test (Agilent kit 103015-100) $1 \mu \mathrm{M}$ oligomycin, $1 \mu \mathrm{M}$ FCCP, $1 \mu \mathrm{M}$ rotenone and $1 \mu \mathrm{M}$ antimycin were sequentially injected at regular intervals. OCR, indicator for mitochondrial respiration, and ECAR, indicative of glycolysis, were measured.

\section{CL-100 ProLiFiler screening}

26 different lung cancer cell lines (Supplementary Table 1) were screened to determine their viability upon treatment with KHS101. The drug was added to the cells one day after seeding and the treatment was performed by nanodrop-dispensing using a Tecan Dispenser. $0.1 \%$ DMSO (solvent) and Staurosporine (1,0E-05 M) served as high control (100\% viability) and low control ( $0 \%$ viability), respectively. After 72 hours of incubation with the compound, cell plates were equilibrated to RT for one hour and CellTiter-Glo ${ }^{\mathrm{TM}}$ Luminescence Cell Viability Reagent (Promega) was added to the cell suspension. The luminescence was measured one hour later using a luminometer. $\mathrm{IC}_{50}$ values were express as percentage of proliferation in presence of solvent alone $(100 \%=$ high control) as compared to cells treated with $1 \mathrm{E}-5 \mathrm{M}$ Staurosporine $(0 \%=$ low control). IC 50 calculation was performed using GraphPad Prism software with a variable slope sigmoidal response fitting model.

\section{Statistical analysis}

Statistical tests were performed with the GraphPad software v.8 comparing groups of different conditions with replicates. In all tests, the statistical significance was set at $p \leq 0.05$.

Additional methods are available in the Supplements.

\section{RESULTS}

\section{HSPD1 is a fitness gene and a potential target for NSCLC}

To understand whether HSPD1 could be an attractive target for NSCLC, we performed a fitness analysis from a previously published dataset of a pan-cancer and genome-wide CRISPR/Cas9 screening of 18,009 genes, which included $n=21$ adenocarcinoma (ADC) and $n=11$ squamous cell carcinoma (SqCC) cell lines (26). As a result, the HSPD1 gene scored very high, ranking $25^{\text {th }}$ in ADC and $71^{\text {th }}$ in SqCC cell lines, out of 805 and 559 total 'fitness' genes, respectively (Fig. 1A). This initial observation was supported by the results from an independent dataset based on a large-scale RNAi screen of 7,837 genes performed in 52 NSCLC cell lines (27), in which HSPD1 resulted to be a significant cancer-dependent gene in over $70 \%$ of the cells (Fig. 1B, Suppl. Table 2), confirming the importance of this gene for NSCLC survival. This importance is also reflected in clinical significance. In fact, survival analysis on HSPD1 mRNA expression 
showed that the patients with high levels of HSPD1 have a worse prognosis compared to those with low HSPD1, in terms of overall (Fig. 1C), relapse-free (Fig. 1D) and disease-specific survival (Fig. 1E). We then investigated the prevalence of HSPD1 expression in tissue samples from a small cohort of NSCLC patients $(n=20)$ by immunohistochemistry (IHC), and measured a positive expression in $100 \%$ of the cases (Fig. 1F-I); expression pattern was cytoplasmic granular or diffuse, with some degree of heterogeneity in terms of intensity (semi quantitatively scored in a three-levels scale), with very high protein levels identified in $45 \%$ of them (Fig. 1J). In order to confirm HSPD1 expression in NSCLC cell lines grown in vitro, a panel of 10 different cell lines, including three mouse-derived (Ladi3.1, LL2 and Ladi2.1) (28), was subjected to western blot quantification, and the results indicated a detectable HSPD1 protein in all samples (Fig.1K). Separated protein isolation from mitochondria and cytosolic fractions confirmed that HSPD1 is predominantly localized in the mitochondria in NSCLC cells (Fig. 1L). Therefore, HSPD1 is a mitochondrial protein essential for NSCLC with a strong prognostic value and high prevalence of expression in tissue samples, making it a very valuable candidate for targeted inhibition.

\section{HSPD1 promotes NSCLC growth in vitro and in vivo}

To study the function of HSPD1 in NSCLC cells in vitro, we analyzed the effects of its knockdown by transducing 5 different NSCLC cell lines with up to 5 independent shRNA sequences (called \#44, \#45, \#46, \#47 and \#48) (Fig. 2A, Suppl. Fig. 1A) and evaluated proliferation through a real-time cell confluency assay (Incucyte system). Shortly after shRNA-based inhibition of HSPD1 expression, the cells showed a decrease in proliferation compared to the controls transduced with a scrambled/non-targeting shRNA, referred to as pLKO (Fig. 2B and Suppl. Fig 1B). In particular, the phenotype was stronger with shRNA sequences providing higher level of HSPD1 suppression (like the \#48). HSPD1 knockdown cells were not able to form colonies compared to the control cells when plated at lower density as observed over two weeks (Fig. 2C-D and Suppl. Fig 1C-D). In line with a strong and durable effect on cell proliferation, a cell cycle analysis showed a significant increase in the percentage of cells in sub-G1 and G1 phases in HSPD1 knockdown cells, in contrast to a reduction in cells residing in S or G2-M phases (Fig. 2E-H, Suppl. Fig. 1E-F).

HSPD1 has a critical function in mitochondrial metabolism (23). Therefore, in order to investigate whether the growth suppression observed with HSPD1 knockdown was linked to metabolic alterations, an extracellular metabolic flux analysis was performed using two different cell lines. Throughout the experiments, knockdown cells showed a significant reduction in their basal respiration and in their ATPlinked respiration, suggesting that the alterations in the mitochondrial metabolism may be responsible for the reduction in cell proliferation (Fig. 3A-B). Finally, we tested if HSPD1 knockdown inhibited cell growth in vivo. To this end, we injected shHSPD1-expressing A549 and H1299 cells subcutaneously in NSG mice to evaluate the tumor growth rate over time. The results clearly indicated that HSPD1 knockdown cells formed very small and slower-growing tumors compared to control pLKO cells, in terms of both tumor 
volume and tumor weight (Fig. $\mathbf{3 C}-\mathbf{H})$, an effect which was maintained for the entire duration of the experiment, confirming that HSPD1 is required for NSCLC growth.

\section{The HSPD1- targeting small molecule KHS101 arrests NSCLC growth}

KHS101 is a synthetic small molecule reported to impair the growth of glioblastoma cells in vitro and in vivo via inhibition of HSPD1 chaperone activity (23). As KHS101 leads to metabolic exhaustion and apoptosis in glioblastoma cells, we first tested as to whether the compound elicits cytotoxicity in NSCLC cell lines. After treatment with KHS101, 6 human NSCLC cell lines showed a significant reduction in cell proliferation that was dependent on the compound concentration (Fig. 4A, Suppl. Fig. 2A-B). To verify the specificity of HSPD1 targeting, we exposed the cells to HB072, an HSPD1 non-targeting chemical analogue (23) (Fig. 4B), which did not significantly affect cell growth (Fig. 4C, Suppl. Fig. 3A). After 5 days of continuous drug treatment, NSCLC cells lost their clonogenic ability, as shown in a colony formation assay (Fig. 4D-E, Suppl. Fig. 3B). In line with HSPD1 knockdown experiments, cell cycle analysis showed a significant reduction in the percentage of cells in S and G2-M phases concomitant with an increase of cells in $\mathrm{G} 1$ phase (Fig. 4F-I), as assessed 24 hours after KHS101 treatment. Finally, since many conventional anticancer therapeutic strategies fail to target non-proliferating cancer cells, we sought to test whether the KHS101-induced growth inhibitory effect was maintained altering the proliferative state of the cells in a controlled fashion. Therefore, after being synchronized overnight using a low FBS concentration (0.5\%), the cells were treated with KHS101 in presence of media with increasing FBS, ranging from $0 \%$ to $5 \%$. As a result, no differences were measured in KHS101 efficacy in the different conditions by a real-time proliferation assay (Suppl. Fig. $\mathbf{3 C}$ ), indicating that KHS101 is effective independently of cells proliferative status. In conclusion, these data indicate that chemical targeting of HSPD1 markedly reduces the growth of NSCLC cell lines.

\section{KHS101 induces metabolic disruption in NSCLC cells leading to cell death}

To test whether KHS101 affects energy metabolism in NSCLC cell lines, we performed an extracellular flux analysis 24 hours after KHS101 treatment. The results indicated a strong reduction in cellular basal respiration and in ATP-coupled respiration capacity. Concomitantly, a significant increase was observed for basal glycolysis (Fig. 5A-B). We next asked as to how fast KHS101 would induce such alterations and treated the cells for shorter periods (ranging from $0.5 \mathrm{~h}$ to $6 \mathrm{~h}$ ), observing that glycolytic activity increases simultaneously with OXPHOS reduction from less than one hour after treatment (Suppl. Fig. 4A-B), and suggesting that the metabolic rewiring induced by KHS101 is an early event, as shown earlier (23). In addition to metabolic flux, cell morphology was found altered in cells exposed to $10 \mu \mathrm{M}$ KHS101. Cells exposed to KHS101 presented an altered ultrastructure. After 96 hours of treatment severe swelling of mitochondria were seen with sparse presence of cristae. As sign of cellular degeneration, an increased number of secondary lysosomes were found. Moreover, there was a loss of microvilli (Fig 5C). However, 
already after 48 hours mitochondria swelling was present, as well as loss of microvilli and in many cells increased number of lysosomes were present, too (Suppl. Fig 4C). As a result of these alteration, and differently to HPSD1 knockdown, KHS101 treatment induced cell death, as indicated by the incorporation of Cytotox fluorescent green dye (Fig 5D, Suppl. Fig. 4D). To test if the affected cells were undergoing apoptosis, we performed a caspase $3 / 7$ activity assay, which showed specific activation of apoptosis 2 days from the start of the treatment (Fig. 5E, Suppl. Fig 4E-F). However, co-administration of the pan-caspase inhibitor Z-VAD-FMK could efficiently suppress caspases activation (Suppl. Fig. 4H), but did not rescue the cells from KHS101 cytotoxicity (Fig. 5F, Suppl. Fig. 4G), indicating that cell death is not occurring solely as a result of apoptotic induction. Interestingly, no protection was observed also in presence of other cell death inhibitors of necroptosis or ferroptosis (Suppl. Fig. 4I-J), suggesting that the metabolic alterations caused by KHS101 induce a cellular breakdown not rescuable by blocking the main cell death pathways. Furthermore, in order to investigate the impact of KHS101 in vivo we first tested the sensitivity of the tumorforming mouse-derived NSCLC cell line LL2 (Suppl. Fig. 5A-B) and subsequently injected them in the tail vein of BL6 mice to evaluate lung metastasis growth upon KHS101 treatment. Lung tumors-bearing mice treated subcutaneously for 2 weeks with $6 \mathrm{mg} / \mathrm{kg} \mathrm{KHS101}$ twice a day did not show a significant difference in tumor area, as evaluated by IVIS measurement, but KHS101-treated mice showed prolonged diseasespecific survival with increased survival time (Suppl. Fig. 5C), in line with a non-significant trend for a reduced number of lung lesions, as macroscopically detected (Suppl. Fig. 5D).

Finally, we investigated the in vitro effects of KHS101 in combination with cisplatin, one of the most commonly used chemotherapeutic drug used in relapsing NSCLC (29). Strikingly, a low cisplatin dose (1 or $3 \mu \mathrm{M}$ ) that alone was not able to strongly impair cell growth or survival, showed to induce a marked growth suppression (Fig. 5G, Suppl. Fig. 6A) and increase in cell death (Fig. 5H, Suppl. Fig. 6B) when combined with KHS101 (also at sub-lethal doses), resulting in a 2 to 4 -fold reduced relative growth compared to cisplatin alone in three different cell lines (Suppl. Fig. 6C). Cisplatin exerts its activity via upregulation of reactive oxygen species (ROS) (30) and by fluorescent ROS staining of treated cells we found that the combination of cisplatin and KHS101 synergistically increased ROS activation (Fig. 5I-J). These data suggest that HSPD1 targeting can also induce cell death and increase the efficacy of chemotherapeutic treatments.

\section{Sensitivity to KHS101 is related to the metabolic state of the cells}

We further profiled in vitro sensitivity to KHS101 by performing a screening on 26 different lung cancer cell lines, measuring cell viability 72 hours after treatment. Interestingly, none of the cell lines in the panel appeared to be completely resistant (Fig. 6A, Suppl. Fig. 7A). KHS101-induced cytotoxicity was independent of the lung cancer type (NSCLC or SCLC) or NSCLC histological subtype (Fig. 6B). However, cells showed different grades of sensitivity towards the compound with $\mathrm{IC}_{50}$ values ranging from 2 to $14 \mu \mathrm{M}$ (Fig. 6C, Suppl. Fig. 7A). These results were independently validated comparing KHS101 sensitivity in the most sensitive and resistant cell lines based on percentage of inhibition of cell proliferation (Suppl. Fig. 
305

306

307

308

309

310

311

312

313

314

315

316

317

318

319

320

321

322

323

324

325

326

327

328

329

330

331

332

333

334

335

336

337

338

339

340

8A). In order to find possible determinants of drug resistance, cell lines with different genetic alterations were compared, but no particular genetic background was found as significantly protective (Supp. Table 3). In order to identify possible molecular determinants of drug sensitivity, we performed a transcriptomic analysis on cell lines based on their IC 50 values. HSPD1 mRNA expression correlated with IC 50 values obtained from the screening (Fig 6D). In order to have a stringent and genome-wide comparison, we used a 2-sided statistical approach. First, the 4 most resistant (NCI-H838, BEN, NCl-H1563 and SK-LU-1) and the 4 most sensitive NSCLC cell lines (H460, NCl-H1581, LOU-NH91 and A549) were grouped and the differentially expressed genes between the two groups were identified and ranked for fold difference (Suppl. Table 4-5). Moreover, using available data from all the cells in the screening, we correlated the expression of each gene with the KHS101 IC 50 values and ranked them based on Pearson metrics (Suppl. Table 6-7). The results from these two analyses were overlapped (Suppl. Fig. 8B), obtaining a list of potential up- and down- regulated genes in cells resistant to KHS101 (Fig. 6E). The top up-regulated resistance-conferring gene was the transcription factor NLRC5, which acts as transactivator for the MHC class I genes (31) (some of which were also up-regulated in the analysis, like HLA-J or HLA-F). To validate this finding, we lentivirally induced NLRC5 overexpression in sensitive NSCLC cells (Fig, 6F), and detected a significantly decreased cytotoxic effect of KHS101, indicating cellular resistance (Fig. 6G, Suppl. Fig. 8C). Among the genes down-regulated in the resistant cell lines, the top hit was SLC6A8 (Fig. 6E), a sodium chloride-dependent creatine transporter 1 (32). This evidence was validated by introducing a specific CRISPR/Cas9-based knock-out of SLC6A8, which increased cells viability of sensitive cell lines treated with KHS101 (Fig. 6H). Since SLC6A8 is a creatine transporter we speculated that it could alter KHS101 sensitivity by changing the metabolic features of the cells. Analysis of a previously published metabolome profiling of NSCLC cell lines (33) revealed that cells that we determined to be the most KHS101 sensitive had a higher creatine level (Fig. 6I), which was consistent with the results from the transcriptomic analysis (i.e. higher expression of the importer) suggesting a possible effect of creatine metabolism in the response to KHS101. Creatine can be phosphorylated by the cytosolic creatine kinase (C-CK) or by the mitochondrial isoenzymes (MtCK) to provide a rapid source of ATP (34) thereby fueling ATP-dependent cellular processes. To test whether differences in cellular creatine levels could be correlated with the cells' metabolic state, we performed extracellular flux analysis of cells with higher (A549 and H460) and lower creatine (H838 and BEN) baseline levels (33) and found that cells with higher creatine had higher basal respiration (Fig.6J). To further functionally prove this correlation, we inhibited creatine kinase activity with the specific inhibitor DNFB which decreased the basal respiration level of A549 cells (Fig. 6K), concomitantly increasing the cells' resistance to KHS101 as assessed by cell viability assays (Fig. 6L). Taken together these findings suggest that a higher dependency on OXPHOS due to the alteration of creatine metabolism activity could determine the sensitivity to KHS101 of NSCLC cells.

\section{KHS101 sensitivity depends on OXPHOS activity}


341 To further investigate KHS101 resistance at a broader level, we performed a genome-wide CRISPR/Cas9-

342 based dropout screening. A genetically barcoded whole-genome library (GeCKO v2) was transduced in 343 A549 cells overexpressing the Cas9 nuclease. These cells were treated with two different KHS101 344 concentrations (10 and $15 \mu \mathrm{M}$ ) or DMSO as control (Fig. 7A). None of the cells were able to survive the 345 treatment with the $15 \mu \mathrm{M}$ KHS101 dose, suggesting that is not possible to develop a complete resistance 346 to this compound by the elimination of a single gene. By contrast, we could observe non-growing and 347 morphologically altered cells surviving the $10 \mu \mathrm{M}$ dose. After 2 weeks of survival (after all control pLKO348 infected Cas9-A549 cells treated with the same KHS101 dose underwent complete cell death), the drug 349 treatment was stopped to allow the selected cells to grow and be processed for the DNA preparation and 350 the next-generation sequencing steps. The sequencing results on untreated cells indicated that it was 351 possible to detect a total of 116700 sgRNAs (all gRNAs excluding those with no counts) present in the 352 library, with a 97\% representation, a level similar to previous screenings (25), while in the treated group this 353 percentage dropped to $56 \%$, as a result of the drug selection. Hits were ranked and gene ontology analysis 354 on the 20 top hits (Supplementary Table 7) indicated that the genes whose knockout increased cellular 355 resistance to KHS101 were mainly involved in mitochondria structure and activity (Fig. 7B). The COX5B gene, a subunit of the cytochrome c oxidase, was the 'top hit'. In order to independently validate this finding, we knocked out COX5B by two independent gRNAs in A549 cells, and in both cases we found the emergence of a more KHS101-resistant phenotype (Fig. 7C). COX5B knock-out cells presented a reduction in their basal respiration and ATP-linked respiration (Fig. 7D), strengthening the notion that KHS101 sensitivity is linked with cellular oxidative activity, in line with the results obtained from creatine metabolism. Conversely, blocking glycolysis by 2-deoxy-D-glucose (2-DG) treatment significantly enhanced KHS101 sensitivity in different cell lines (Fig. 7E), further confirming that cancer cells respond to KHS101 proportionally to their OXPHOS-dependence. Therefore, HSPD1 targeting induces a mitochondrial metabolic breakdown in NSCLC, which results in loss of growth potential and cell death, and the small molecule KHS101 is particularly active on OXPHOS-dependent cells.

\section{DISCUSSION}

The identification of novel targets and the development of more effective drugs is of paramount importance for improving the clinical management of NSCLC. Metabolism has recently gained much attention in the oncological field and anti-metabolism strategies have been proposed to reduce the lethal effects of NSCLC (35-37). We report here heat shock protein HSPD1 as a theranostic metabolic marker for NSCLC, whose

374 Heat shock proteins (HSPs) are molecular chaperones categorized according to their molecular sizes into 375 small HSPs and large HSPs (16). HSPs can be highly expressed in cancer cells, where they promote cell 376 proliferation, metastasization and drug resistance, HSPD1 is an ATP-dependent HSP mainly localized in 377 the mitochondria, playing an essential role in guaranteeing the correct folding of the mitochondrial-imported 
proteins (38) and some data are available on its role as a stemness/metastasis regulator in other cancers $(22,39,40)$. In lung cancer, HSPD1 has been previously found highly expressed in NSCLC tissues (41) and identified as a predictive marker for survival in both smokers and non-smokers patients (42). Our findings confirm that HSPD1 is ubiquitously expressed at a high level (as detectable by IHC in all samples) and is associated with adverse prognosis, adding the notion that its expression is essential for NSCLC survival (fitness gene), making it a very attractive target for future therapy. In order to more functionally explore this possibility we evaluated the effect of HSPD1 targeting achieved by either shRNA-mediated knockdown or by a specific small molecule. In shRNA experiments, the level of growth suppression measured for each shRNA sequence was generally proportional to the degree of HSPD1 knockdown. Importantly, even if a complete protein elimination was not achieved, the cell growth blockage obtained by the best performing shRNA (\#48) was durable (up to one month) and very effective both in vitro and in vivo in all the cell lines investigated. When cellular metabolic changes were measured, cells with HSPD1 knockdown presented a strong reduction in basal respiration and impaired capacity in synthesizing ATP though OXPHOS, in line with the role of HSPD1 in the (re)folding of mitochondrial-imported oxidative respiration proteins (43). The activity of HSPD1 is therefore essential for maintaining NSCLC metabolic fitness and its loss causes a profound energetic breakdown affecting the ability of the cancer cells to divide and expand.

An emerging way of chemically disrupting the functionality of HSPD1 is the treatment with the synthetic small compound KHS101. This compound was originally identified through a phenotypical screen as an inducer of neuronal differentiation both in vitro and in vivo (44). KHS101 promotes HSPD1 aggregation thereby altering the metabolic activity of glioblastoma cells (23). In NSCLC, we observed that KHS101treated cells were very severely growth arrested, in analogy to what was observed with the HSPD1 knockdown approach. OXPHOS activity was also efficiently repressed, even with low micromolar KHS101 concentrations, starting from a few hours after treatment. In contrast to HSPD1 knockdown, KHS101treated cells increased glycolysis, suggesting that they might try to compensate for the loss of ATP production. This increase is, however, not sufficient for the cells to gain resistance and survive the treatment. Indeed, KHS101-treated cells underwent significant cell death, probably due to the formation of irreversible HSPD1 multi-aggregates coagulated by KHS101, as shown (23). Notably, co-administration of specific inhibitors of death pathways did not rescue KHS101 treated cells, indicating that the occurring death is strong, multifactorial, and irreversible, all features of crucial importance for a novel anti-cancer

408 In order to better understand the biology of HSPD1 targeting, two independent unbiased screenings were 409 carried out: a differential gene expression analysis on KHS101 sensitive and resistant cells and a genome410 wide CRISPR/Cas9-based dropout screening on drug treated cells. The first approach identified a 411 biomarker of increased sensitivity, the creatine importer SLC6A8, which lead us to discover OXPHOS 412 dependency as condition for better KHS101 efficacy. Moreover, a potential role in determining KHS101 413 resistance of the MHC class I genes transactivator NLRC5 as been here identified. Based on its importance 414 on inflammatory processes in tumors (31), the molecular details of this link should be in the future 
determined. The second approach came independently to a similar and converging conclusion, by identifying mitochondrial metabolism genes, and in particular the subunit of the cytochrome c oxidase complex (COX5B), as enriched in cells surviving KHS101. All these evidences highlight the targeting of mitochondrial metabolism as an effective therapeutic strategy to achieve a complete, irreversible elimination of NSCLC.

The occurrence of drug-overcoming mutations is a typical feature of NSCLC, which has unfortunately so far limited the success of targeted therapies (45). Here, noteworthy, not a single cell from the whole-genome CRISPR/Cas9 library was able to survive the KHS101 selection when administered at the highest dose (15 $\mu \mathrm{M})$. At the lowest dose $(10 \mu \mathrm{M})$, a small population of cells was able to persist, but could not grow (and be processed for sequencing) until the drug was entirely removed from the experiment. This is a very important observation in line with the observed inability of death pathways inhibitors to protect in vitro from KHS101, and in line with the data from the two independent fitness analyses on HSPD1 gene and with the drug screening from large collections of NSCLC cell lines of various genetic backgrounds, which confirmed that no single genetic alteration can guarantee a complete protection from the treatment with KHS101. The sensitivity towards KHS101 is also independent from the lung cancer type or NSCLC histotype, suggesting that a HSPD1 targeting approach might be valuable also for other cancer types. Another aspect of fundamental importance to consider for NSCLC drug development is the potential successful combination with chemotherapy, as chemotherapy still represents the backbone of therapeutic regimens, especially in late-stage lung cancer patients (46-48). Even if the data here presented will require future dedicated experimentation, the results are encouraging, as KHS101 showed to act synergistically with cisplatin in vitro, enhancing the production of reactive oxygen species and reducing the dose of cisplatin needed to slow down or kill the cancer cells. All these evidences reinforce the potential relevance of designing and developing HSPD1-targeting drugs for NSCLC therapy. This goal, however, is not likely to be achieved by KHS101 itself, which this study found active at relatively higher concentrations. KHS101 therefore stands out as a rather excellent tool compound for accelerating discoveries for HSPD1 targeting, but novel drugs (or modifications of the same compound) with improved affinity will need to be designed and tested, for instance by taking advantage of emerging targeting techniques based on induction of selective intracellular proteolysis $(49,50)$. The activity of these drugs could be in the future tested beyond NSCLC, as HSPD1 appears to be a fundamental oncoprotein also in other contexts $(39,40)$.

In conclusion, we showed that HSPD1 elimination interferes with NSCLC metabolic activity causing a strong OXPHOS-dependent energetic breakdown, which the cancer cells fail to overcome, highlighting HSPD1 as a powerful theranostic marker for improving lung cancer therapy.

\section{COMPETING INTERESTS}

The authors declare no competing interests. 


\section{AUTHORS' CONTRIBUTIONS}

452 Conception and design: B.P, P. C.; Development of methodology: B.P, V.R, P.G, A.S, L.P, A.S, S.M, S.Z,

453 C.P, S.U, D.M, H.S, H.W, P. C.; Acquisition of data (provided animals, acquired and managed patients,

454 provided facilities, etc.): F.N, M.V, S.U, D.M, M.S; Analysis and interpretation of data (e.g., statistical

455 analysis, biostatistics, computational analysis):B.P, V.R, P.C; Writing, review, and/or revision of the

manuscript: B.P, H.W, P.C ; Administrative, technical, or material support (i.e., reporting or organizing

data, constructing databases): V.R, P.G, A.S, S.M, S.Z, P.C, S.U, D.M, M.S, H.W, P.C. Study

supervision: P. C. The author(s) read and approved the final manuscript.

\section{REFERENCES}

1. Bray F, Ferlay J, Soerjomataram I, Siegel RL, Torre LA, Jemal A. Global cancer statistics 2018: GLOBOCAN estimates of incidence and mortality worldwide for 36 cancers in 185 countries. CA Cancer J Clin 2018;68:394-424

2. Herbst RS, Morgensztern D, Boshoff C. The biology and management of non-small cell lung cancer. Nature 2018;553:446-54

3. Kleczko EK, Kwak JW, Schenk EL, Nemenoff RA. Targeting the Complement Pathway as a Therapeutic Strategy in Lung Cancer. Front Immunol 2019;10

4. Osmani L, Askin F, Gabrielson E, Li QK. Current WHO guidelines and the critical role of immunohistochemical markers in the subclassification of non-small cell lung carcinoma (NSCLC): Moving from targeted therapy to immunotherapy. Semin Cancer Biol 2018;52:103-9

5. Duma N, Santana-Davila R, Molina JR. Non-Small Cell Lung Cancer: Epidemiology, Screening, Diagnosis, and Treatment. Mayo Clin Proc 2019;94:1623-40

6. Luengo A, Abbott KL, Davidson SM, Hosios AM, Faubert B, Chan SH, et al. Reactive metabolite production is a targetable liability of glycolytic metabolism in lung cancer. Nat Commun 2019;10:5604

7. Vander Heiden MG, DeBerardinis RJ. Understanding the Intersections between Metabolism and Cancer Biology. Cell 2017;168:657-69

8. Yu L, Lu M, Jia D, Ma J, Ben-Jacob E, Levine H, et al. Modeling the Genetic Regulation of Cancer Metabolism: Interplay between Glycolysis and Oxidative Phosphorylation. Cancer Res 2017;77:1564-74

9. Faubert B, Solmonson A, DeBerardinis RJ. Metabolic reprogramming and cancer progression. Science 2020;368

10. Kim J, DeBerardinis RJ. Mechanisms and Implications of Metabolic Heterogeneity in Cancer. Cell Metab 2019;30:434-46

11. Jin N, Bi A, Lan X, Xu J, Wang X, Liu Y, et al. Identification of metabolic vulnerabilities of receptor tyrosine kinases-driven cancer. Nat Commun 2019;10:2701

12. Fenouille N, Bassil CF, Ben-Sahra I, Benajiba L, Alexe G, Ramos A, et al. The creatine kinase pathway is a metabolic vulnerability in EVI1-positive acute myeloid leukemia. Nat Med 2017;23:301-13 
13. Bader DA, Hartig SM, Putluri V, Foley C, Hamilton MP, Smith EA, et al. Mitochondrial pyruvate import is a metabolic vulnerability in androgen receptor-driven prostate cancer. Nat Metab 2019;1:70-85

14. Jacob P, Hirt H, Bendahmane A. The heat-shock protein/chaperone network and multiple stress resistance. Plant Biotechnol J 2017; 15:405-14

15. Dubrez L, Causse S, Borges Bonan N, Dumetier B, Garrido C. Heat-shock proteins: chaperoning DNA repair. Oncogene 2020;39:516-29

16. Chatterjee S, Burns TF. Targeting Heat Shock Proteins in Cancer: A Promising Therapeutic Approach. Int J Mol Sci 2017;18

17. Wu J, Liu T, Rios Z, Mei Q, Lin X, Cao S. Heat Shock Proteins and Cancer. Trends Pharmacol Sci 2017;38:226-56

18. Gomez-Llorente $\mathrm{Y}$, Jebara F, Patra M, Malik R, Nisemblat S, Chomsky-Hecht O, et al. Structural basis for active single and double ring complexes in human mitochondrial Hsp60-Hsp10 chaperonin. Nat Commun 2020;11:1916

19. Teng R, Liu Z, Tang H, Zhang W, Chen Y, Xu R, et al. HSP60 silencing promotes Warburg-like phenotypes and switches the mitochondrial function from ATP production to biosynthesis in ccRCC cells. Redox Biol 2019;24:101218-

20. Yun CW, Kim HJ, Lim JH, Lee SH. Heat Shock Proteins: Agents of Cancer Development and Therapeutic Targets in Anti-Cancer Therapy. Cells 2019;9

21. Xu X, Wang W, Shao W, Yin W, Chen H, Qiu Y, et al. Heat shock protein-60 expression was significantly correlated with the prognosis of lung adenocarcinoma. J Surg Oncol 2011;104:598603

22. Fucarino A, Pitruzzella A. Role of HSP60/HSP10 in Lung Cancer: Simple Biomarkers or Leading Actors? J Oncol 2020;2020:4701868

23. Polson ES, Kuchler VB, Abbosh C, Ross EM, Mathew RK, Beard HA, et al. KHS101 disrupts energy metabolism in human glioblastoma cells and reduces tumor growth in mice. Sci Transl Med 2018;10

24. Siddiqui A, Gollavilli PN, Schwab A, Vazakidou ME, Ersan PG, Ramakrishnan M, et al. Thymidylate synthase maintains the de-differentiated state of triple negative breast cancers. Cell Death Differ 2019;26:2223-36

25. Gollavilli PN, Parma B, Siddiqui A, Yang H, Ramesh V, Napoli F, et al. The role of miR-200b/c in balancing EMT and proliferation revealed by an activity reporter. Oncogene 2021

26. Behan FM, lorio F, Picco G, Goncalves E, Beaver CM, Migliardi G, et al. Prioritization of cancer therapeutic targets using CRISPR-Cas9 screens. Nature 2019;568:511-6

27. McDonald ER, 3rd, de Weck A, Schlabach MR, Billy E, Mavrakis KJ, Hoffman GR, et al. Project DRIVE: A Compendium of Cancer Dependencies and Synthetic Lethal Relationships Uncovered by Large-Scale, Deep RNAi Screening. Cell 2017;170:577-92 e10

28. Siddiqui MA, Gollavilli PN, Ramesh V, Parma B, Schwab A, Vazakidou ME, et al. Thymidylate synthase drives the phenotypes of epithelial-to-mesenchymal transition in non-small cell lung cancer. Br J Cancer 2021;124:281-9

29. Senan S, Brade A, Wang LH, Vansteenkiste J, Dakhil S, Biesma B, et al. PROCLAIM: Randomized Phase III Trial of Pemetrexed-Cisplatin or Etoposide-Cisplatin Plus Thoracic Radiation Therapy Followed by Consolidation Chemotherapy in Locally Advanced Nonsquamous Non-Small-Cell Lung Cancer. J Clin Oncol 2016;34:953-62

30. Kim SJ, Kim HS, Seo YR. Understanding of ROS-Inducing Strategy in Anticancer Therapy. Oxid Med Cell Longev 2019;2019:5381692

31. Benko S, Kovacs EG, Hezel F, Kufer TA. NLRC5 Functions beyond MHC I Regulation-What Do We Know So Far? Front Immunol 2017;8:150 
32. Ji L, Zhao X, Zhang B, Kang L, Song W, Zhao B, et al. Slc6a8-Mediated Creatine Uptake and Accumulation Reprogram Macrophage Polarization via Regulating Cytokine Responses. Immunity 2019;51:272-84 e7

33. Li H, Ning S, Ghandi M, Kryukov GV, Gopal S, Deik A, et al. The landscape of cancer cell line metabolism. Nat Med 2019;25:850-60

34. Snow RJ, Murphy RM. Creatine and the creatine transporter: a review. Mol Cell Biochem 2001;224:169-81

35. Ramesh V, Brabletz T, Ceppi P. Targeting EMT in Cancer with Repurposed Metabolic Inhibitors. Trends in cancer 2020;6:942-50

36. Kawada K, Toda K, Sakai Y. Targeting metabolic reprogramming in KRAS-driven cancers. Int J Clin Oncol 2017;22:651-9

37. Obrist F, Michels J, Durand S, Chery A, Pol J, Levesque S, et al. Metabolic vulnerability of cisplatinresistant cancers. The EMBO journal 2018;37

38. Marino Gammazza A, Macaluso F, Di Felice V, Cappello F, Barone R. Hsp60 in Skeletal Muscle Fiber Biogenesis and Homeostasis: From Physical Exercise to Skeletal Muscle Pathology. Cells 2018;7

39. Tsai YP, Yang MH, Huang CH, Chang SY, Chen PM, Liu CJ, et al. Interaction between HSP60 and beta-catenin promotes metastasis. Carcinogenesis 2009;30:1049-57

40. Berger $\mathrm{E}$, Rath $\mathrm{E}$, Yuan $\mathrm{D}$, Waldschmitt N, Khaloian S, Allgäuer $\mathrm{M}$, et al. Mitochondrial function controls intestinal epithelial stemness and proliferation. Nat Commun 2016;7:13171

41. Michils A, Redivo M, Zegers de Beyl V, de Maertelaer V, Jacobovitz D, Rocmans P, et al. Increased expression of high but not low molecular weight heat shock proteins in resectable lung carcinoma. Lung Cancer 2001;33:59-67

42. Sotgia F, Lisanti MP. Mitochondrial markers predict survival and progression in non-small cell lung cancer (NSCLC) patients: Use as companion diagnostics. Oncotarget 2017;8:68095-107

43. Zhou C, Sun H, Zheng C, Gao J, Fu Q, Hu N, et al. Oncogenic HSP60 regulates mitochondrial oxidative phosphorylation to support Erk1/2 activation during pancreatic cancer cell growth. Cell Death Dis 2018;9:161

44. Wurdak H, Zhu S, Min KH, Aimone L, Lairson LL, Watson J, et al. A small molecule accelerates neuronal differentiation in the adult rat. Proc Natl Acad Sci U S A 2010;107:16542-7

45. Lim ZF, Ma PC. Emerging insights of tumor heterogeneity and drug resistance mechanisms in lung cancer targeted therapy. J Hematol Oncol 2019;12:134

46. Pirker R. Chemotherapy remains a cornerstone in the treatment of nonsmall cell lung cancer. Curr Opin Oncol 2020;32:63-7

47. Visconti R, Morra F, Guggino G, Celetti A. The between Now and Then of Lung Cancer Chemotherapy and Immunotherapy. Int J Mol Sci 2017;18

48. Scagliotti GV, Ceppi P, Capelletto E, Novello S. Updated clinical information on multitargeted antifolates in lung cancer. Clin Lung Cancer 2009;10 Suppl 1:S35-40

49. Khan S, He Y, Zhang X, Yuan Y, Pu S, Kong Q, et al. PROteolysis TArgeting Chimeras (PROTACs) as emerging anticancer therapeutics. Oncogene 2020;39:4909-24

50. Sun X, Gao H, Yang Y, He M, Wu Y, Song Y, et al. PROTACs: great opportunities for academia and industry. Signal Transduct Target Ther 2019;4:64

51. Siddiqui A, Vazakidou ME, Schwab A, Napoli F, Fernandez-Molina C, Rapa I, et al. Thymidylate synthase is functionally associated with ZEB1 and contributes to the epithelial-to-mesenchymal transition of cancer cells. J Pathol 2017;242:221-33

52. Sanjana NE, Shalem O, Zhang F. Improved vectors and genome-wide libraries for CRISPR screening. Nature methods 2014;11:783-4

53. Li W, Xu H, Xiao T, Cong L, Love MI, Zhang F, et al. MAGeCK enables robust identification of essential genes from genome-scale CRISPR/Cas9 knockout screens. Genome Biol 2014;15:554 
54. Chen EY, Tan CM, Kou Y, Duan Q, Wang Z, Meirelles GV, et al. Enrichr: interactive and collaborative HTML5 gene list enrichment analysis tool. BMC Bioinformatics 2013;14:128

\section{FIGURE LEGENDS}

Figure 1. Heat shock protein HSPD1 is a fitness gene with prognostic power ubiquitously expressed in NSCLC tumors and cell lines A) Fitness score for HSPD1 in lung adenocarcinoma (ADC) and squamous cell carcinoma (SqCC). Each dot represents a single gene. B) RSA (redundant siRNA activity) waterfall plot of HSPD1 sensitivity score from PROJECTDRIVE showing HSPD1 as an essential gene in non-small cell lung cancer (NSCLC) cell lines ( $n=52)$. RSA sensitivity score $<-3$. C) Overall survival analysis between the low- and high-HSPD1 groups in TCGA LUAD ( $N=510)$ and GSE30219 ( $N=293)$. P-value was calculated using log-rank test. Relapse-free (D) and disease-specific (E) survival analysis between lowand high-HSPD1 groups in GSE30219 ( $\mathrm{N}=293)$ and TCGA LUAD ( $\mathrm{N}=510)$, respectively. P-value was calculated using log-rank test. Time is expressed as months. IHC staining of HSPD1 in cancer tissues (F, $\mathrm{G}, \mathrm{H}$ and $\mathrm{I}$ ) derived from consecutive 20 lung cancer patients (peritumoral bronchial structure in upper right corner of panel F). J) Pie chart of HSPD1 predominant intensity in patient-derived adenocarcinoma samples. K) Western blot quantification of HSPD1 in a panel of different human (A549, Calu-1, SK-MES-1, H460, H520, H1299 and H23) and mouse (Ladi2.1, LL2 and Ladi3.1) NSCLC cells. $\beta$-Actin was used as loading control. L) Western blot analysis of HSPD1 in cytosolic (named as C) or mitochondrial (named as M) fraction. $\beta$-Actin was used as loading control and TOMM20 was used as control for cytosolic/mitochondrial fractionation.

Figure 2. HSPD1 knockdown blocks cell proliferation and clonogenic ability of NSCLC cells A) Western blot analysis of HSPD1 protein levels in A549, H1299 and H460 cells upon infection with 3 independent shRNA (\#44, \#45 and \#48) targeting HSPD1 compared to scramble-infected cells (pLKO). $\beta$ Actin was used as loading control. B) Real-time proliferation curves of A549, H1299 and H460 infected with non-targeting pLKO or shHSPD1. Plotted is the cells' confluency over time. P-values are from two-way ANOVA. Points $(n=5)$ are average \pm SD. ${ }^{*}<0.05,{ }^{* *}<0.01,{ }^{* * *}<0.001,{ }^{* * * *}<0.0001$. Colony formation of A549 (C) and H1299 (D) cells with pLKO or shHSPD1, stained with crystal-violet and quantified in triplicates. Scale bars are average \pm SD. P-values are from unpaired $t$-test. ${ }^{* *}<0.01,{ }^{* * *}<0.001$. FACS plots of A549 (E) and H1299 (F) cells infected with pLKO or shHSPD1 and stained with PI for cell cycle analysis. Bar graph showing the \% of cells in each cell cycle phase of A549 $(\mathrm{G})$ and $\mathrm{H} 1299(\mathrm{H})$ cells upon infection with pLKO or shHSPD1. P-values are from two-way ANOVA. Scale bars $(n=3)$ are average \pm SD. ${ }^{* *}<0.01$, $* * *<0.001$.

Figure 3. HSPD1 knockdown induces a metabolic breakdown and reduces tumor growth in vivo Quantification of basal respiration, indicative glycolysis and ATP-linked respiration of H1299 (A) and A549 
(B) shHSPD1 cells compared to pLKO cells. Bars $(n=5)$ are average \pm SD. P-values are from unpaired $t$ test. ${ }^{*}<0.05,{ }^{* * * *}<0.0001$. Images of tumors from NSG mice injected subcutaneously with $\mathrm{H} 1299$ (C) or A549 (F) pLKO or shHSPD1 cells. Graph showing tumor growth of H1299 (D) or A549 (G) shHSPD1 cells compared to pLKO cells. P-value is from two-way ANOVA. Points $(n=8)$ are average \pm SD. ${ }^{* * * *}<0.0001$. Bar graph showing weight of H1299 (E) and A549 (H) shHSPD1 tumors compared to pLKO tumors. Bars $(n=8)$ are average \pm SD. P-value is from unpaired $t$-test. ${ }^{* * * *}<0.0001$.

Figure 4. The small HSPD1-targeting molecule KSH101 induces cell growth arrest A) Real-time HB072 synthetic molecular structures. C) Real-time proliferation curves of Calu-1 cells treated either with KHS101 or with the corresponding inactive KHS101 analog (HB072) compared to vehicle-treated cells. Pvalues are from two-way ANOVA. Points $(n=3)$ are average \pm SD. ${ }^{* * * *}<0.0001$. Colony formation of H460 drug-free media, then stained with crystal-violet and quantified in triplicates. Scale bars are average \pm SD. P-values are from unpaired $t$-test. ${ }^{* * *}<0.001,{ }^{* * * *}<0.0001$. FACS plots of $A 549(\mathrm{~F})$ and $\mathrm{H} 460(\mathrm{H})$ treated 24 hours with KHS101 and stained with PI for cell cycle analysis. Bar graph showing the \% of cells in each cell cycle phase of $A 549(G)$ and $H 460$ (I) cells treated 24 hours with vehicle or KHS101. P-values are from two-way ANOVA. Scale bars $(n=3)$ are average $\pm S D$. ${ }^{* *}<0.01,{ }^{* * * *}<0.0001$.

Figure 5. KHS101 induces a metabolic breakdown and death in NSCLC cells Bar graphs showing quantification of basal respiration, indicative glycolysis and ATP-linked respiration in A549 (A) or Calu-1 (B) treated with KHS101 for 24 hours compared to control cells (DMSO). Bars $(n=5)$ are average \pm SD. Pvalues are from unpaired $t$-test. ${ }^{*}<0.05,{ }^{* *}<0.01,{ }^{* * *}<0.001,{ }^{* * * *}<0.0001$. C) Electron microscopy images of A549 treated 96 hours either with vehicle (DMSO) or KHS101 $10 \mu \mathrm{M}$, (M: mitochondria, V: microvilli). D)

647 Dead cell quantification as green object count using Cytotox green reagent (D) or caspse-3/7 reagent (E) 648 of vehicle or KHS101 treated A549 cells. F) Dead cell quantification as green object count of A549 treated either with DMSO or KHS101 in combination with pan-caspase inhibitor Z-VAD-FMK. In D, E and F points $(n=5)$ are average \pm SD. P-value are from two-way ANOVA. ${ }^{* \star * *}<0.0001$. G) Real-time proliferation curves of A549 and H460 treated with KHS101 and/or cisplatin compared to control cells. Death is shown as green

652 object count in $\mathrm{H})$. Points $(\mathrm{n}=5)$ are average \pm SD. P-value are from two-way ANOVA. ${ }^{* * *}<0.0001$. 653 Percentage of ROS-positive cells in A549 cells treated with KHS101 and/or cisplatin for 24 hours are shown 654 in FACS plots (I) and a graph bar (J). P-values are from one-way ANOVA. Scale bars $(\mathrm{n}=3)$ are average \pm 655 SD. ${ }^{*}<0.05$. 
660

661

662

663

664

665

666

667

668

669

670

671

672

673

674

675

676

677

678

679

680

681

682

683

684

685

686

687

688

689

690

691

692

are shown with $95 \%$ confidence intervals. B) Bar graph showing the average $\mathrm{IC}_{50}$ for each NSCLC histotype and SCLC. Bars are average \pm SD. P-values are from one-way ANOVA. C) Dose-response curves of the 4 more sensitive cell lines (H460, NCl-H1581, LOU-NH91, A549) compared to the 4 more resistant cell lines (NCl-H838, BEN, NCl-H1563, SK-LU-1) resulted from the screening. Points are average \pm SD. D) Correlation between HSPD1 gene expression and KHS101 IC 50 values in a panel of NSCLC cell lines from GSE47206 (n=13). E) Genes with most differential expression between KHS101-sensitive and KHS101resistant groups ( $\log _{2}$ fold change cut-off of 4 and $p$-value $\left.<0.05\right) F$ ) Western blot analysis of NLRC5 protein level in A549 cells overexpressing NLRC5 or empty vector. $\beta$-Actin was used as loading control. G) Doseresponse curves (normalized to DMSO control) of A549 expressing NLRC5 compared to empty control cells. Points $(n=4)$ are average $\pm S D$. IC 50 values $(\mu M)$ are shown. P-values are from two-way ANOVA. ${ }^{* * * *}<0.0001$. H) Dose-response curves (normalized to DMSO control) of A549 SLC6A8 KO compared to control cells. Points $(n=4)$ are average \pm SD. $I_{50}$ values $(\mu M)$ are shown. P-values are from two-way ANOVA. ${ }^{* * * *}<0.0001$ I) Metabolite analysis between KHS101-sensitive and KHS101-resistant cells with a $\log _{10}$ fold change of 2 and $p$-value $<0.05$. J) Metabolic phenogram showing OCR (basal respiration) and ECAR (indicative glycolysis) values of creatine high (H460, A549) and creatine low (BEN, H838) cells. K) Metabolic phenogram showing OCR and ECAR levels in A549 treated for 24 hours with creatine-kinase inhibitor (DNFB). L) Dose-response curves (normalized to DMSO control) of A549 and H460 cells in presence of creatine-kinase inhibitor DNFB. Points $(n=3)$ are average \pm SD. IC 50 values $(\mu M)$ are shown. P-values are from two-way ANOVA. ${ }^{*}<0.05,{ }^{* * *}<0.001$.

\section{Figure 7 Mitochondrial metabolism influences NSCLC cells response to KHS101 A) Scheme showing} the genome-wide CRISPR-Cas9 screening platform employed to identify KHS101 resistance genes. B) Gene ontology (GO) analysis of the top 20 candidates identified from the knockout screen in cells after treatment with KHS101. GO was performed with the cellular component 2017b gene set library in Enrichr tool. C) Dose-response curves to KHS101 (normalized to DMSO control) of A549 cells overexpressing two gRNAs to knockout COX5B, compared to parental A549. Points $(n=4)$ are average \pm SD. IC 50 values $(\mu M)$ are shown. P-values are from two-way ANOVA. * $<0.05$. D) Bar graphs showing quantification of basal respiration, indicative glycolysis and ATP-linked respiration of A549 COX5B knockout cells compared to parental cells. Bars $(n=5)$ are average \pm SD. P-values are from unpaired $t$-test. ${ }^{* \star *}<0.001,{ }^{* \star * *}<0.0001$. E) Dose-response curves (normalized to DMSO control) of A549, H460 and H1299 cells in presence of glycolysis inhibitor 2-deoxy-D-glucose (2-DG). Points $(n=3)$ are average $\pm S D$. IC 50 values $(\mu M)$ are shown. P-values are from two-way ANOVA. ${ }^{* \star * *}<0.0001$. F) Schematic representation of the metabolic alteration that occur in NSCLC cells upon HSPD1 loss. 
Figure 2 available under aCC-BY-NC-ND 4.0 International license.

A

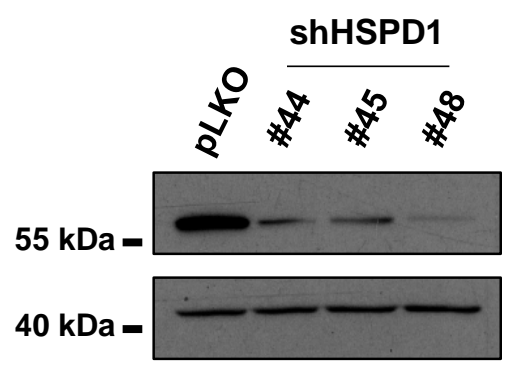

A549

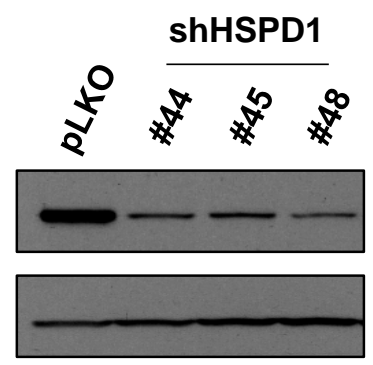

H1299

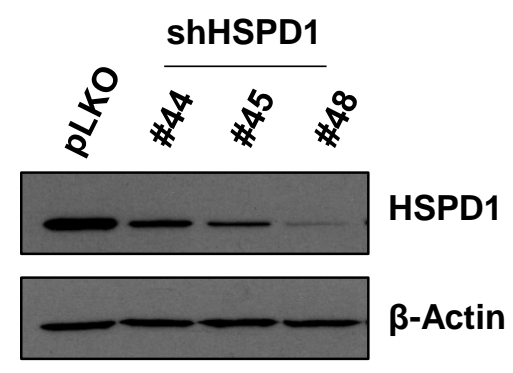

H460

B

A549

H1299

H460
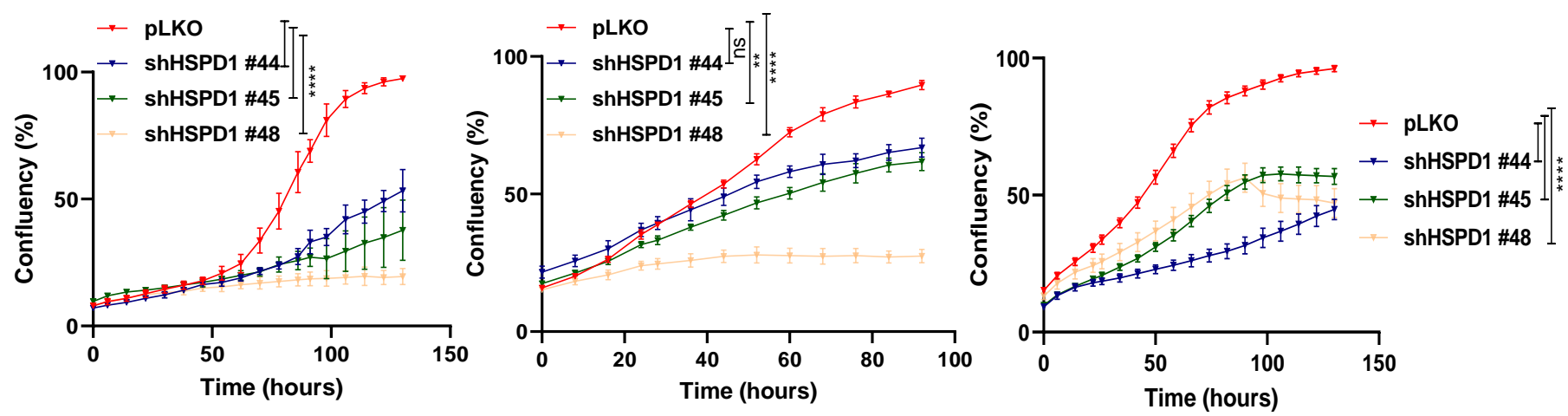

C

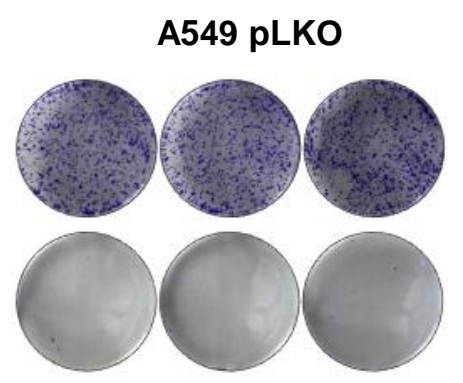

A549 shHSPD1 \#48

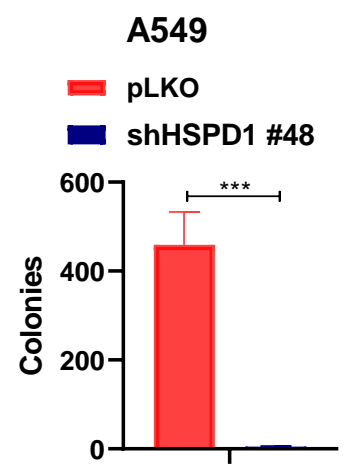

E

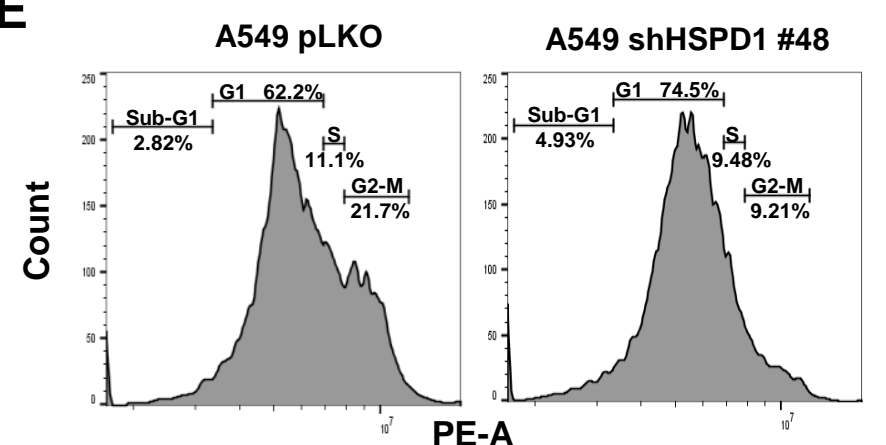

G

A549

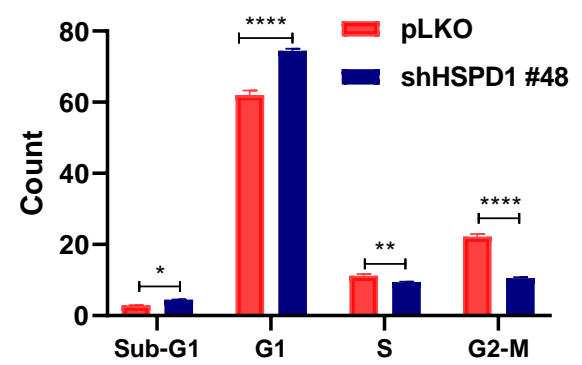

D

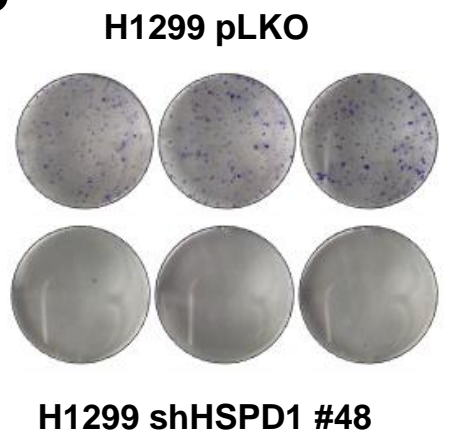

F

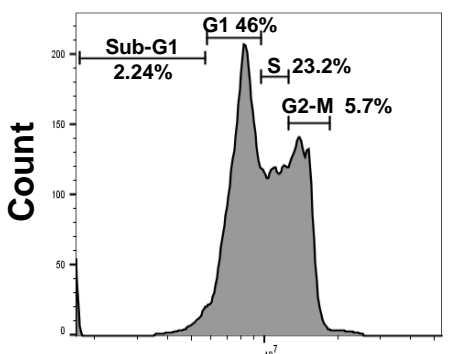

PE-A

H

H1299
H1299

pLKO

shHSPD1 \#48

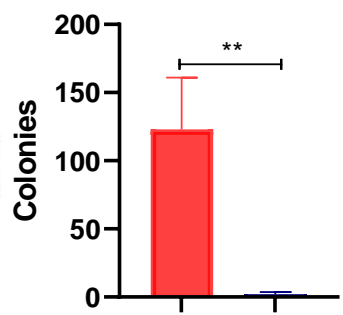

H1299 shHSPD1 \#48
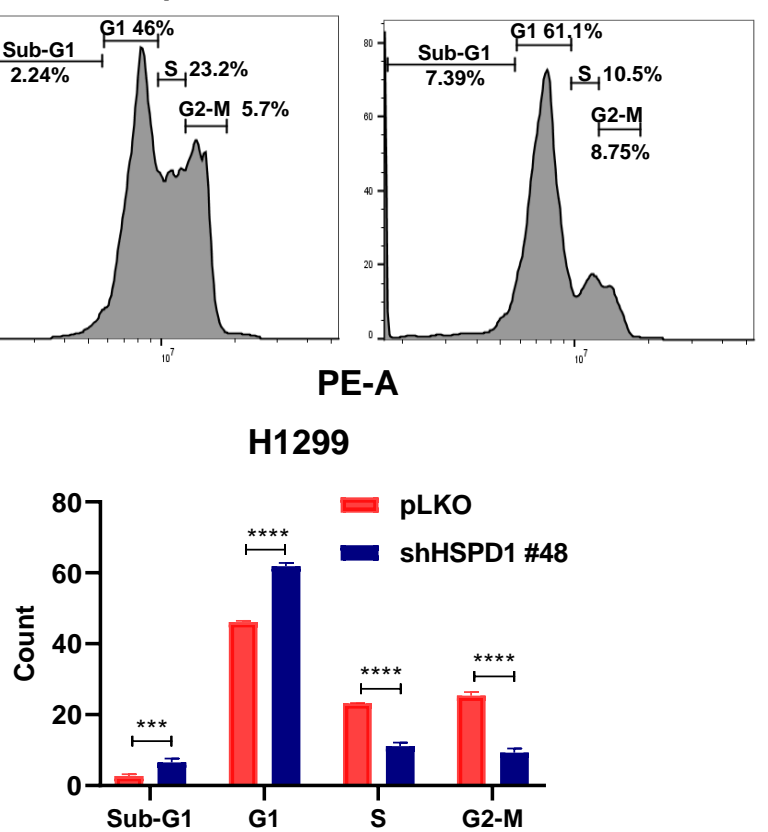
Figure 3

A

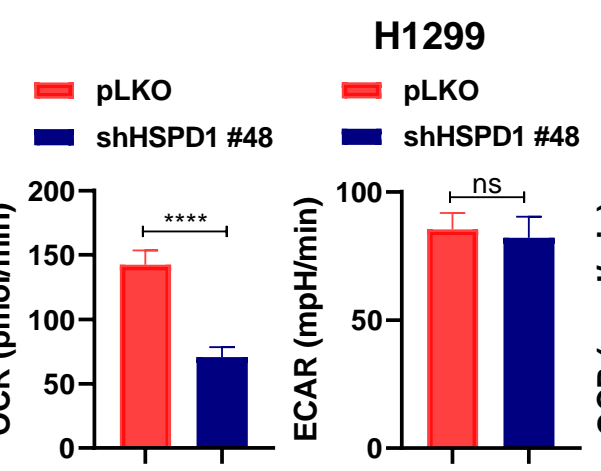

Basal respiration Indicative glycolysis

C
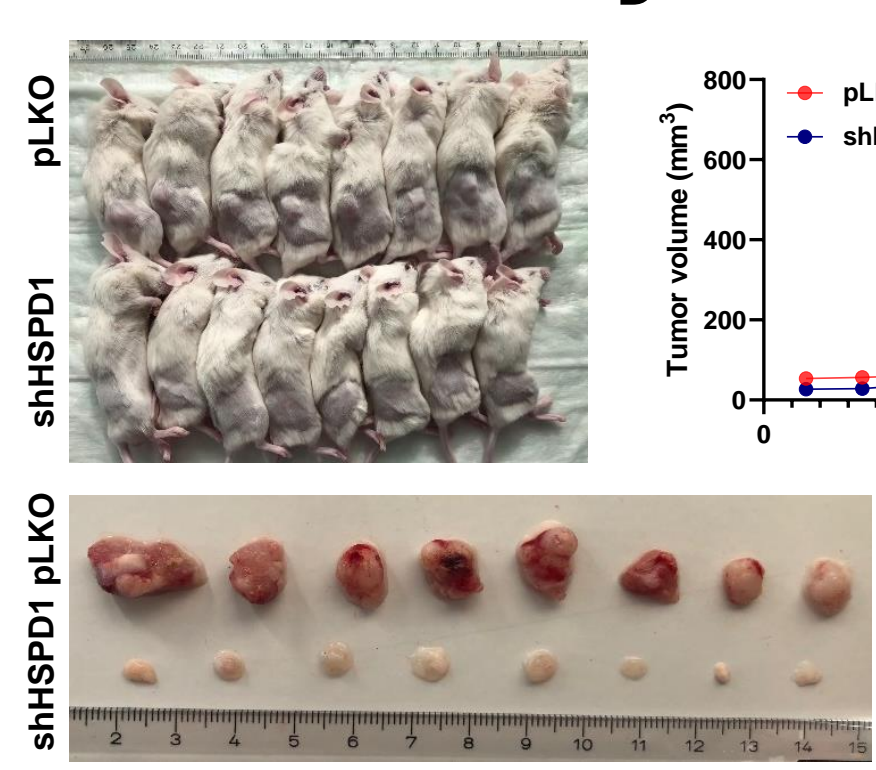

$\mathbf{F}$

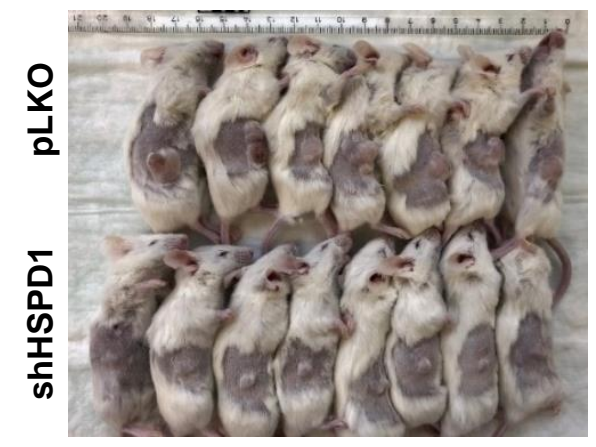

ATP-linked respiration

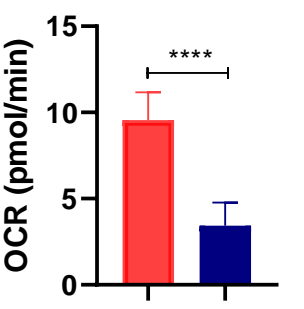

Basal respiration Indicative glycolysis
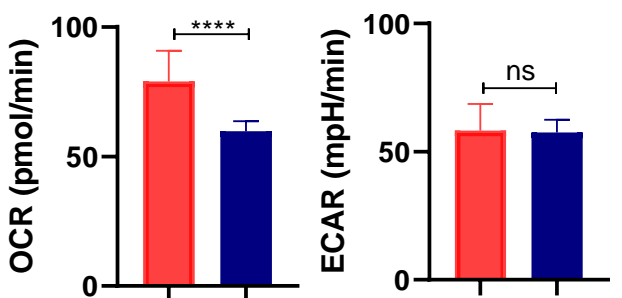

G

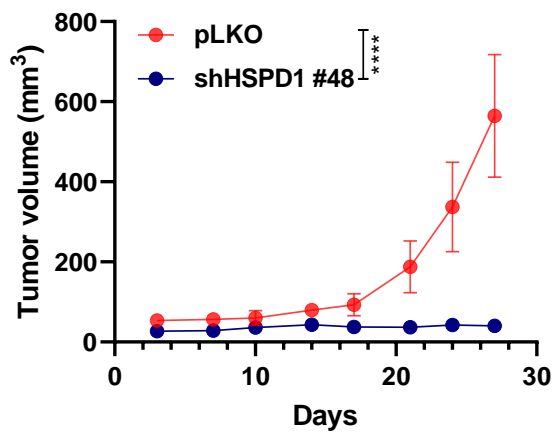

D

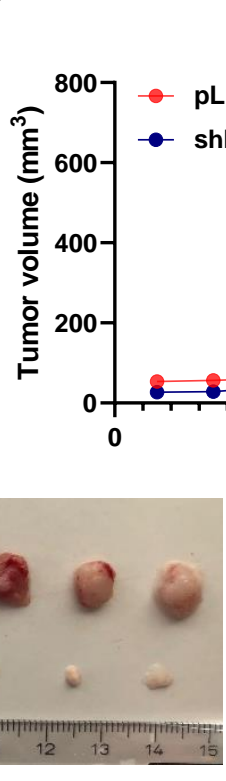

$\mathbf{E}$

\section{H1299}
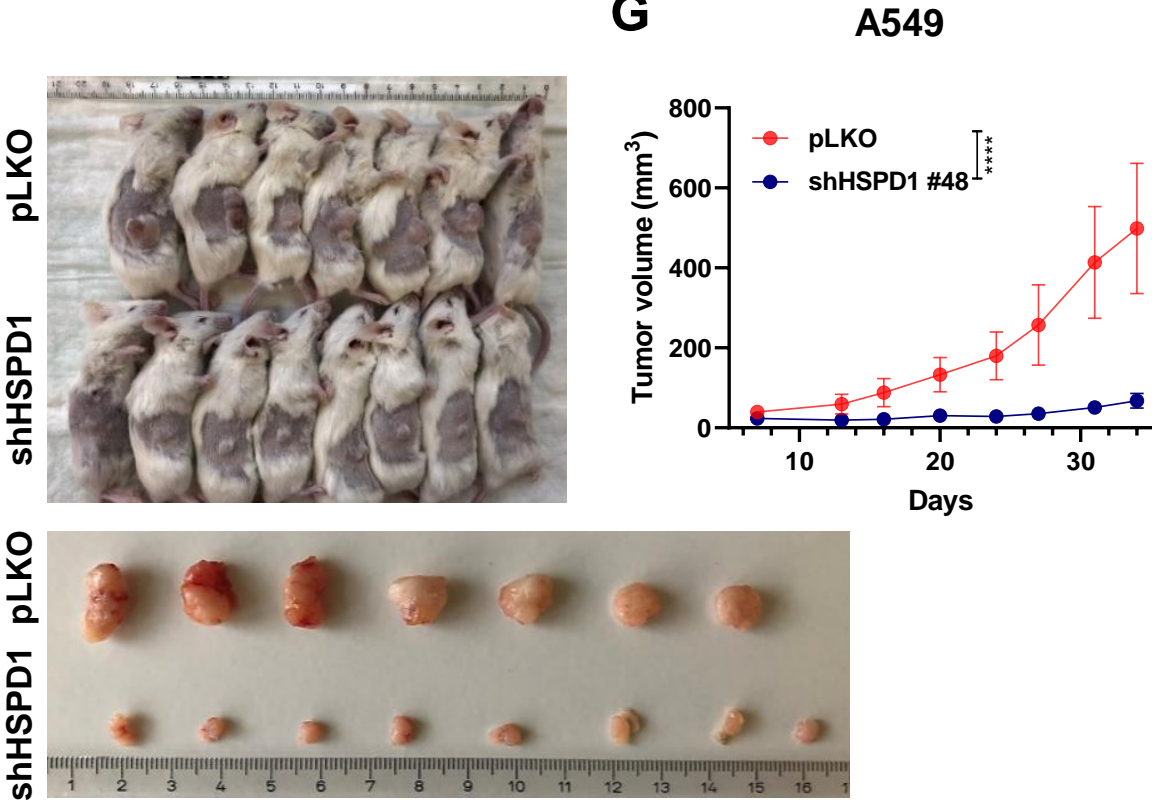

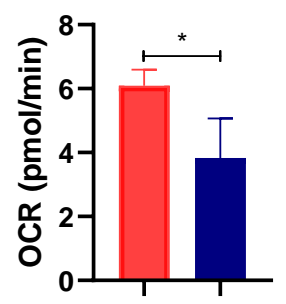

ATP-linked

respiration

\section{A549}

D PLKO DLKO

- shHSPD1 \#48 
Figure 5 available under aCC-BY-NC-ND 4.0 International license.

A

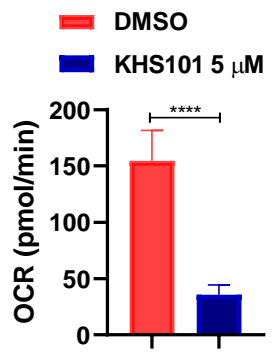

Basal respiration Indicative glycolysis

C

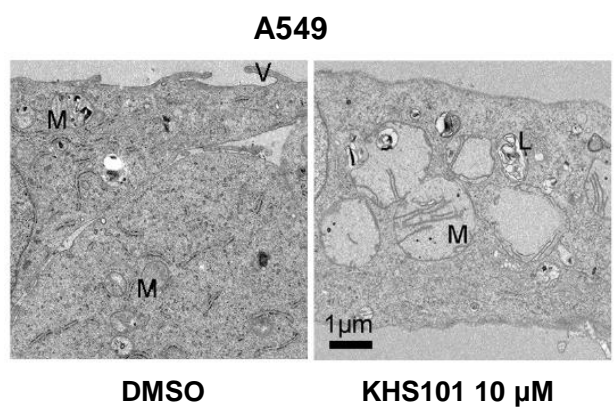

$\mathbf{F}$

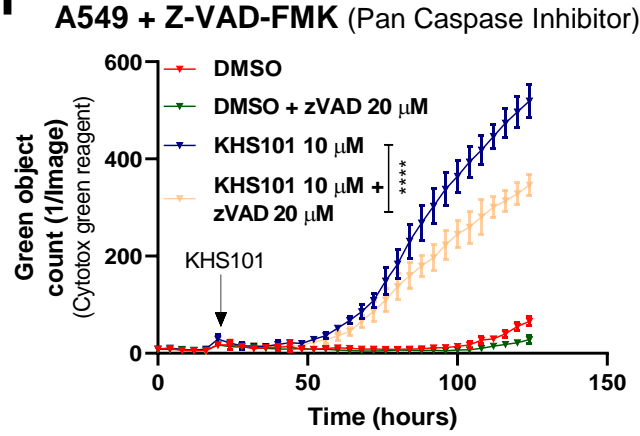

D DMSO

KHS101 $5 \mu \mathrm{M}$
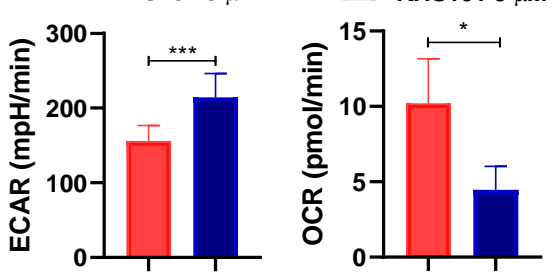

ATP-linked respiration
B
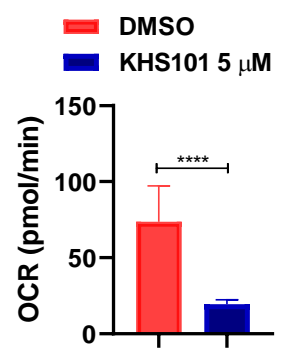

Basal respiration

Calu-1

D

A549

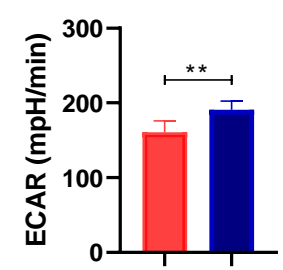

Indicative glycolysis

E

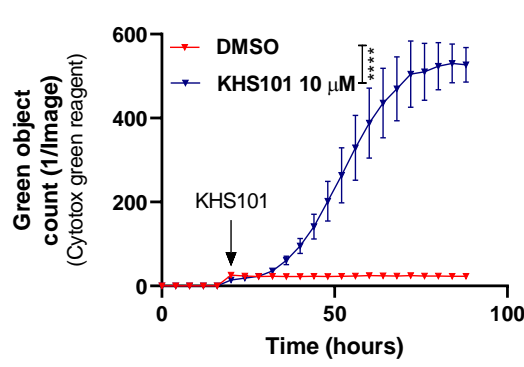

G

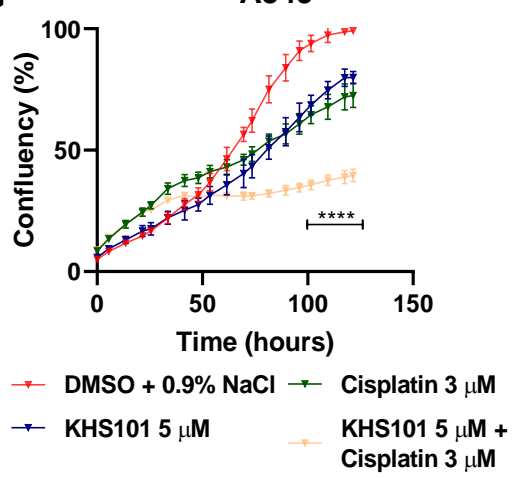

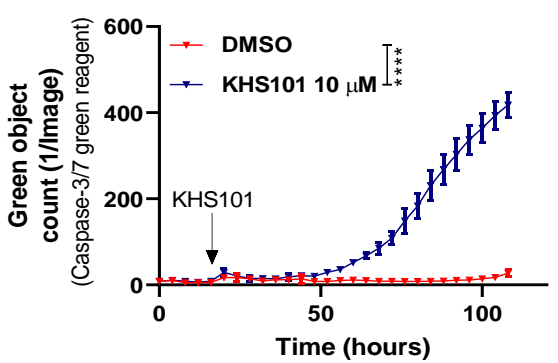

H460

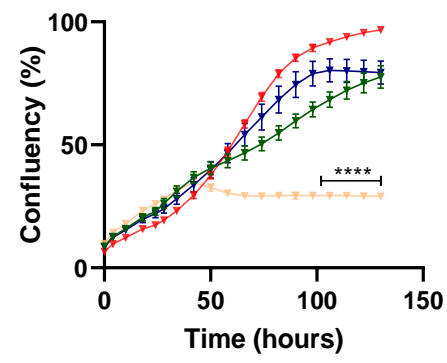

$\rightarrow \mathrm{DMSO}+0.9 \% \mathrm{NaCl} \rightarrow$ Cisplatin $1 \mu \mathrm{M}$

$\rightarrow \mathrm{KHS1013 \mu \textrm {M }}$ KHS101 $3 \mu \mathrm{M}+$ Cisplatin $1 \mu \mathrm{M}$

H

A549

H460
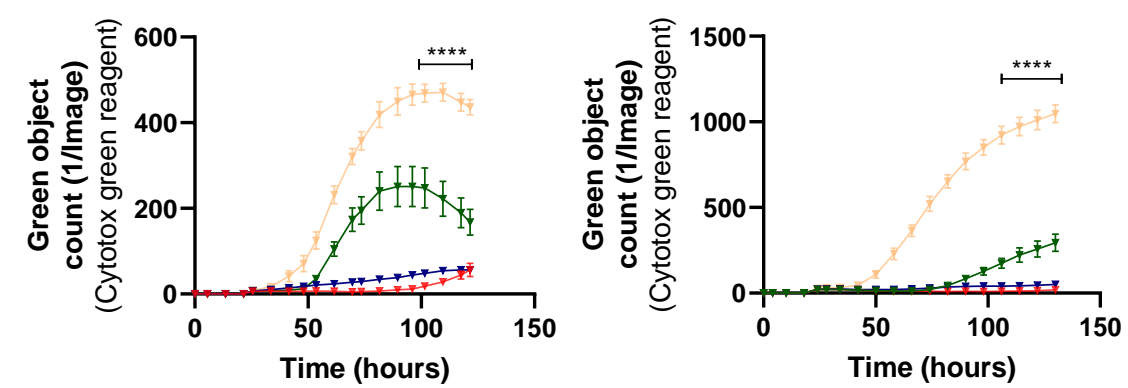

- DMSO + 0.9\% NaCl $\rightarrow$ Cisplatin $3 \mu \mathrm{M}$

- DMSO + 0.9\% NaCl $\rightarrow$ Cisplatin $1 \mu \mathrm{M}$

$\rightarrow \mathrm{KHS1015 \mu \textrm {M }}$

KHS101 $5 \mu \mathrm{M}+$
Cisplatin $3 \mu \mathrm{M}$

KHS101 $3 \mu \mathrm{M}$

KHS101 $3 \mu \mathrm{M}+$

Cisplatin $1 \mu \mathrm{M}$

J

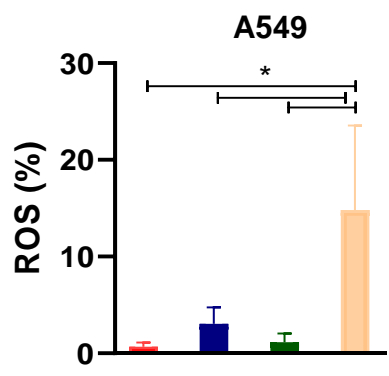

CTR

KHS101 $5 \mu \mathrm{M}$

Cisplatin $3 \mu \mathrm{M}$

KHS101 $5 \mu \mathrm{M}+$

Cisplatin $3 \mu \mathrm{M}$
A549

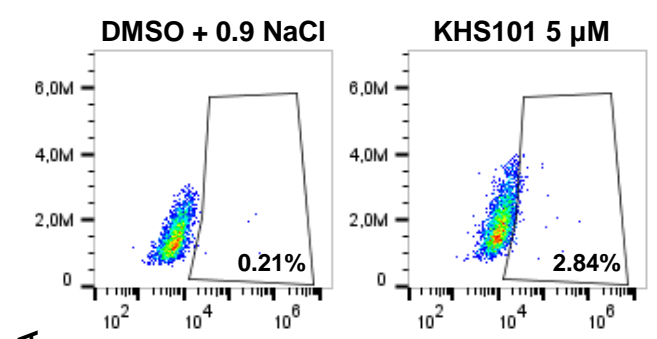

ङ

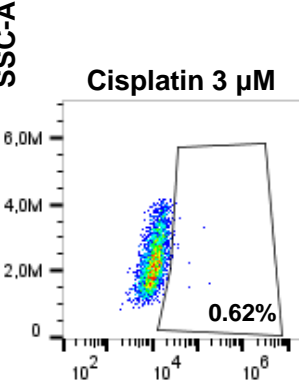

KHS101 $5 \mu \mathrm{M}+$

Cisplatin $3 \mu \mathrm{M}$

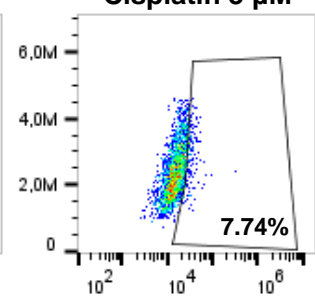

FITC-A 


\section{Figure 6}

available under aCC-BY-NC-ND 4.0 International license.
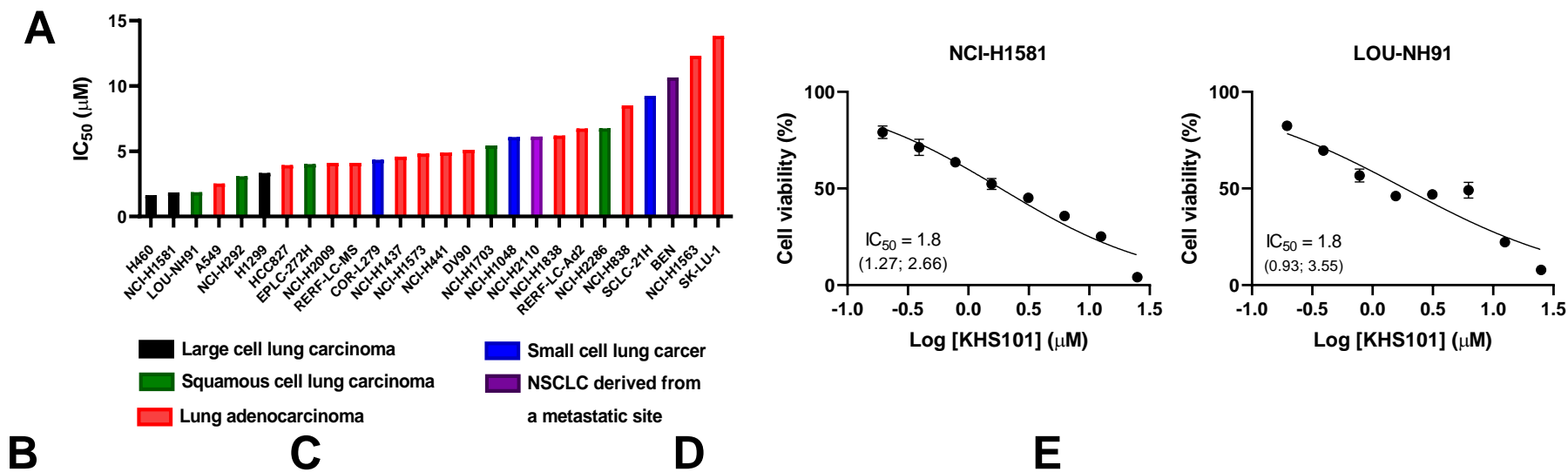

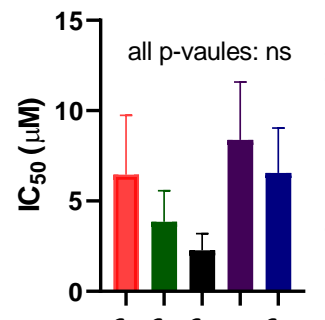

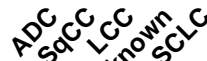
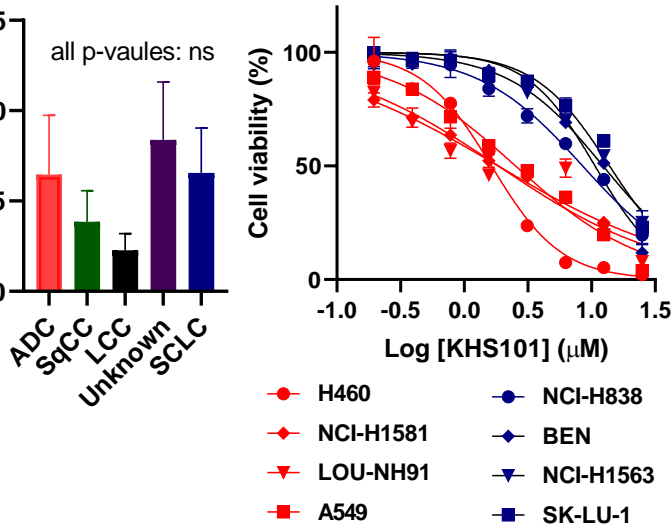

$\mathbf{F}$

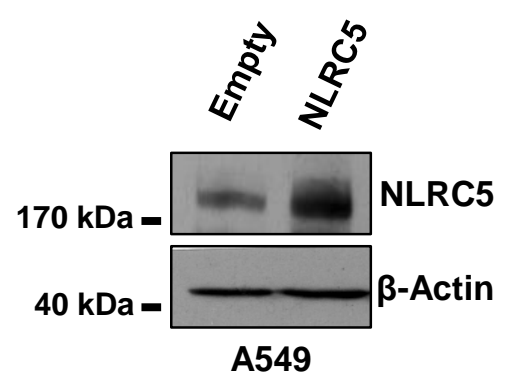

G

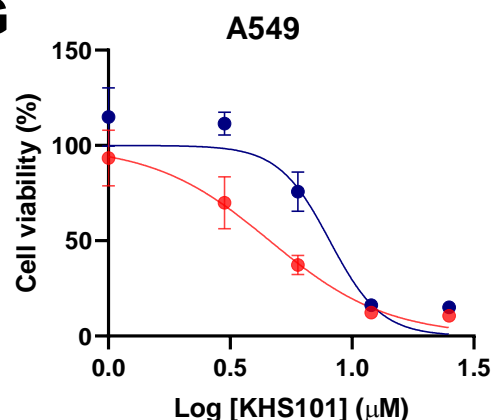

$\rightarrow$ A549 Empty $\rightarrow I_{50}=4.59{ }^{*}$

$\longrightarrow$ A549 NLRC5 $\rightarrow \mathrm{IC}_{50}=8.1$

\begin{tabular}{lcc}
\hline \multicolumn{1}{c}{ Genes } & Correlation & $\begin{array}{c}\text { Differential gene } \\
\text { exp status }\end{array}$ \\
NLRC5 & 0.777 & UP \\
TAPBPL & 0.754 & UP \\
HLA-J & 0.718 & UP \\
HLA-F & 0.707 & UP \\
P2RX5 & -0.521 & DOWN \\
SLC6A8 & -0.604 & DOWN \\
\hline
\end{tabular}

H

A549

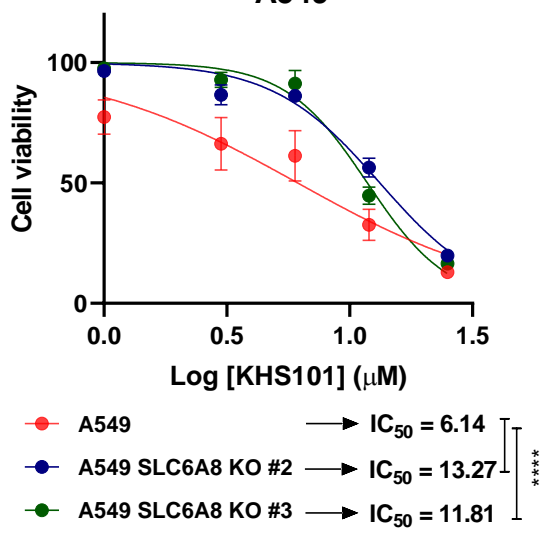

\begin{tabular}{lcc}
\hline \multicolumn{1}{c}{ Metabolites } & Folds & p-value \\
guanosine & 3.54 & 0.045 \\
C18:0 LPE & 2.26 & 0.009 \\
putrescine & -2.12 & 0.006 \\
hexanoylcarnitine & -2.12 & 0.029 \\
creatine & -2.59 & 0.041 \\
carnitine & -2.64 & 0.010 \\
\hline
\end{tabular}

K

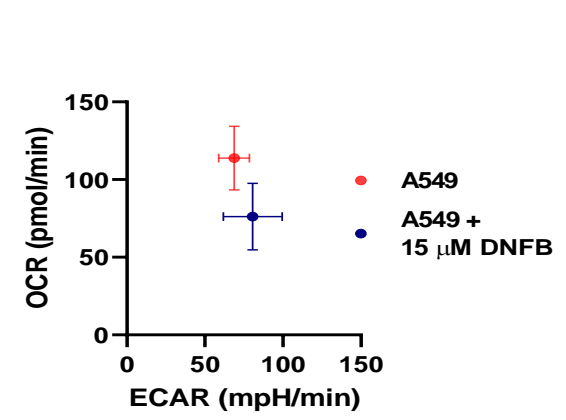

L

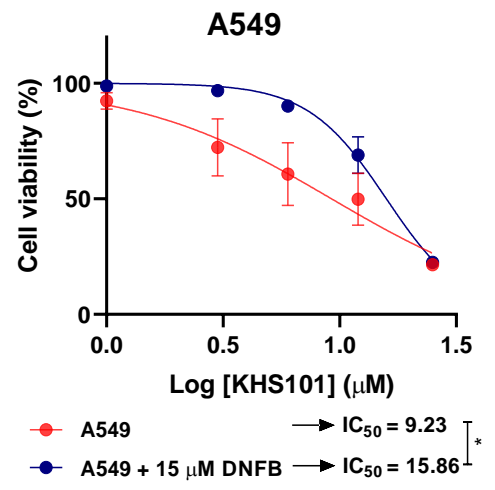

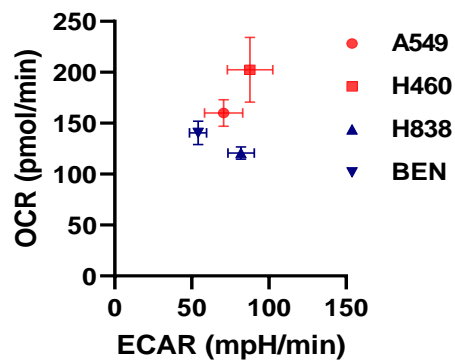

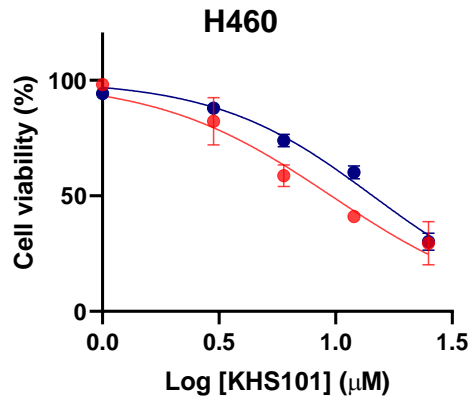


Figure 7 available under aCC-BY-NC-ND 4.0 International license.

A

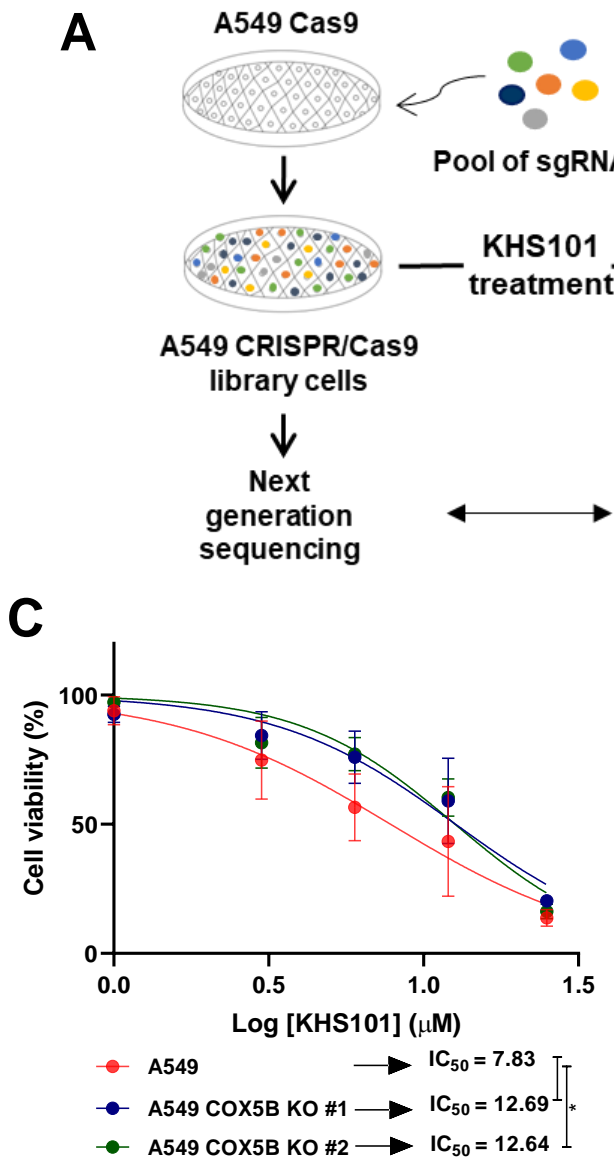

E

C

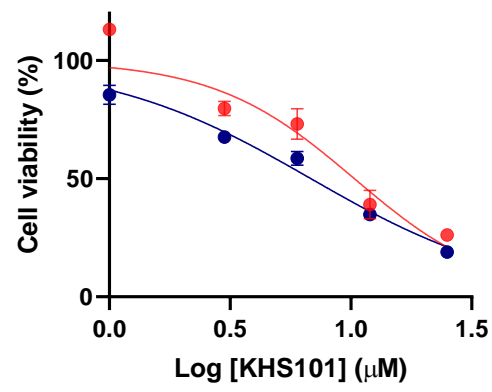

$\begin{array}{ll}\longrightarrow \text { A549 } & \longrightarrow \mathrm{IC}_{50}=10.34 \\ \rightarrow \mathrm{A} 549+1 \mathrm{mM} 2-\mathrm{DG} & \longrightarrow \mathrm{IC}_{50}=6.83\end{array}$

F

\section{F}

\section{B}

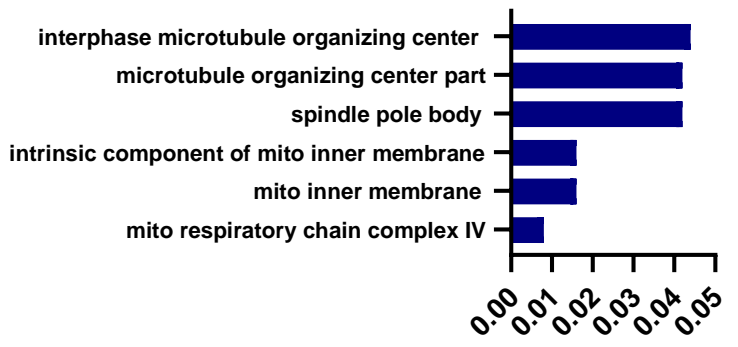

Next

generation

sequencing

D

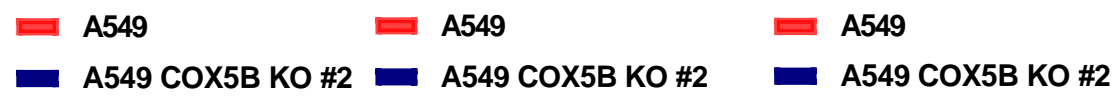

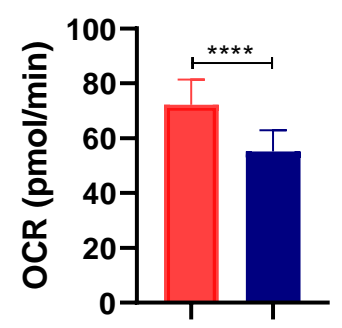

Basal respiration Indicative glycolysis

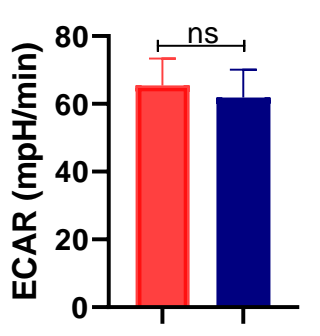

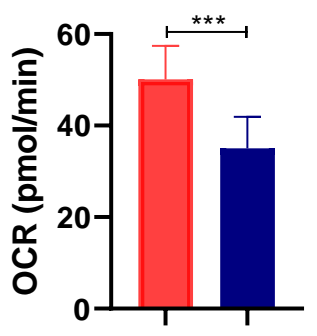

ATP-linked respiration
H460

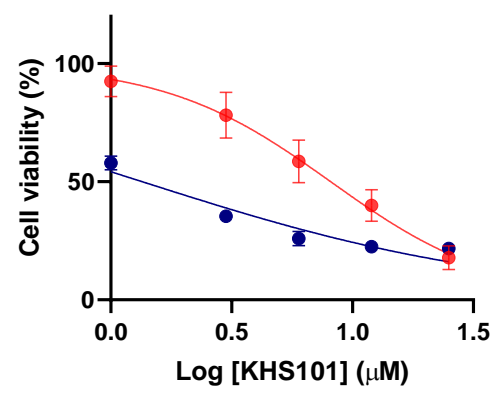

$\begin{array}{ll}\longrightarrow \mathrm{H} 460 & \longrightarrow \mathrm{IC}_{50}=8.13 \\ \rightarrow \mathrm{H} 460+1 \mathrm{mM} 2-\mathrm{DG} & \longrightarrow \mathrm{IC}_{50}=1.35\end{array}$
H1299

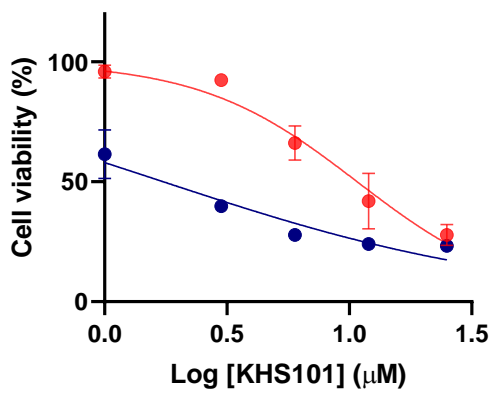

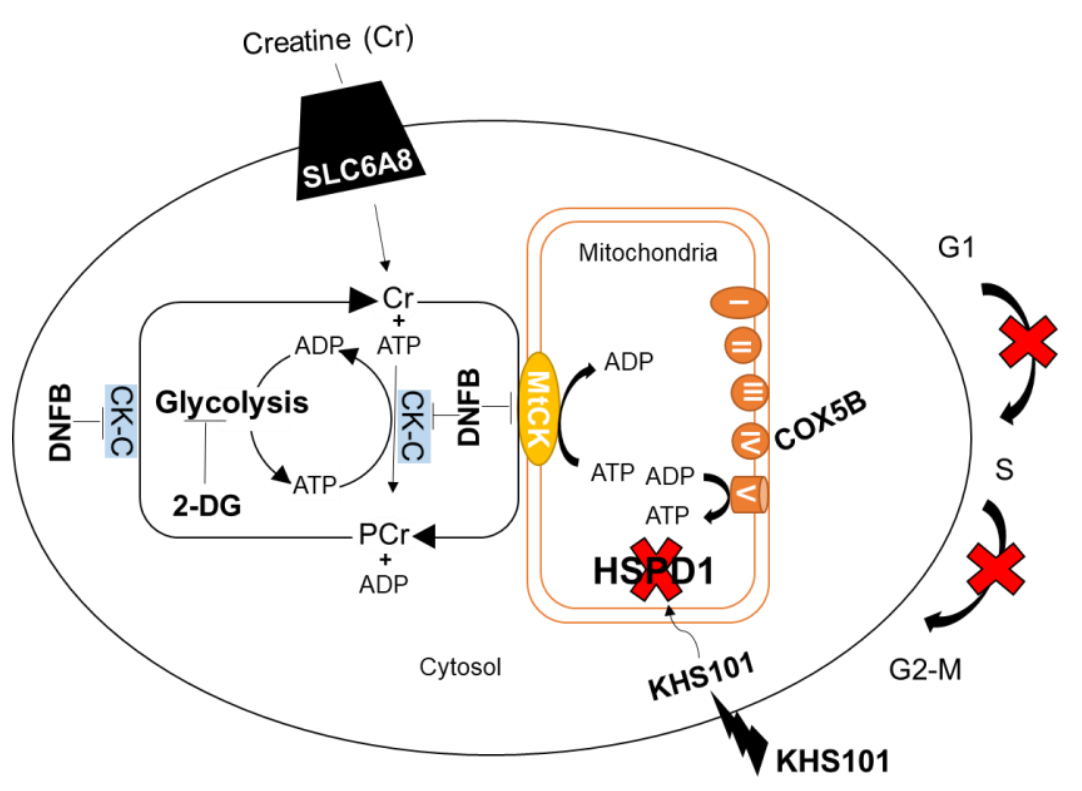




\section{Supplementary Figure 1}

A

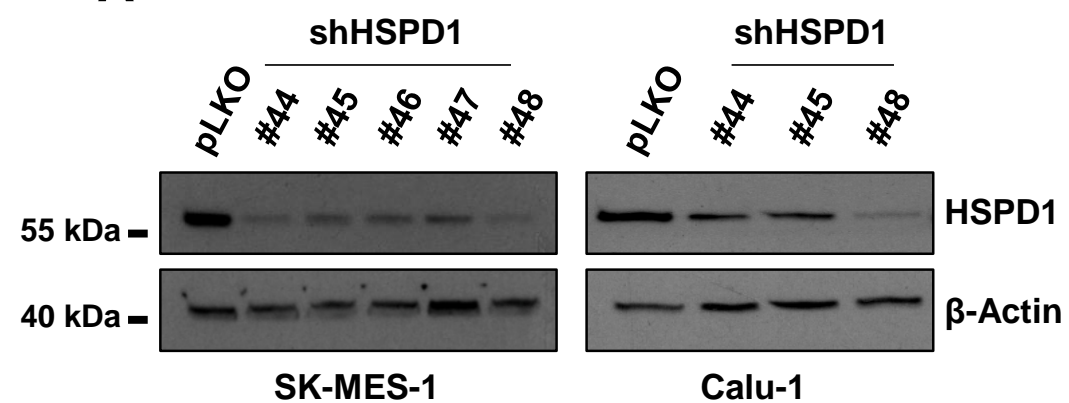

SK-MES-1

SK-MES-1

Calu-1
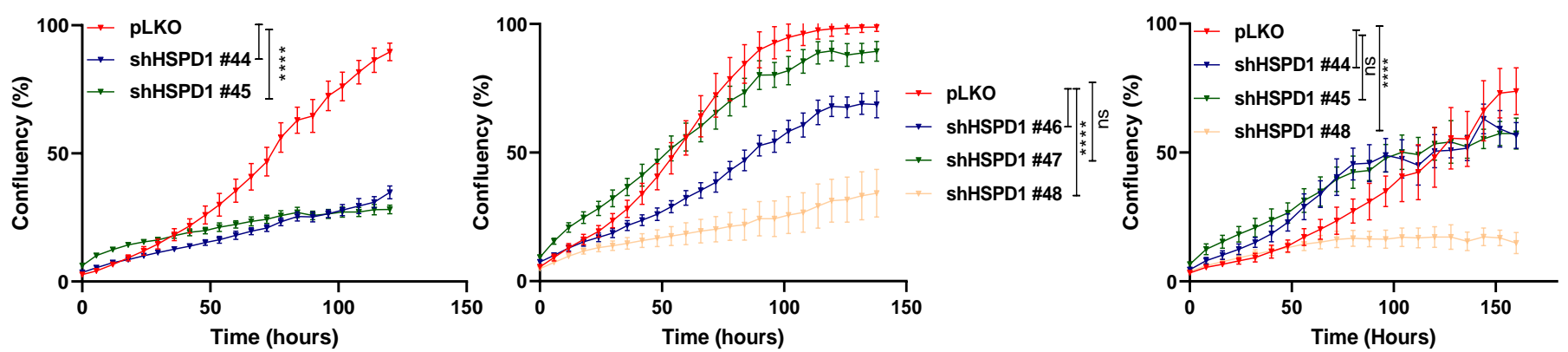

C

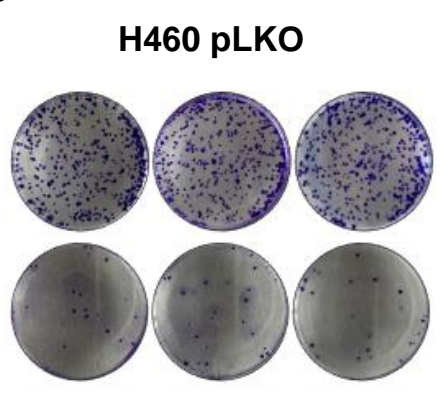

H460 shHSPD1 \#48

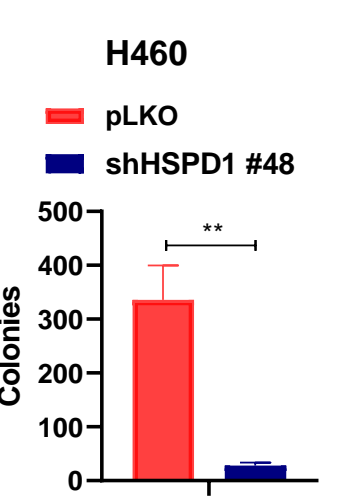

D

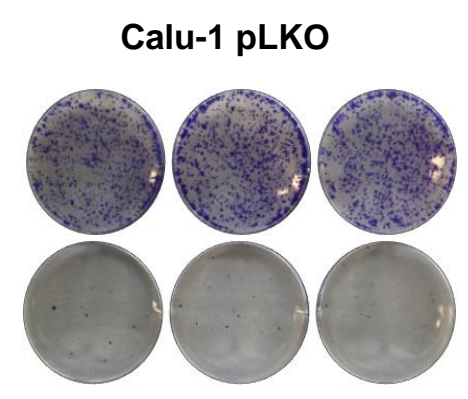

Calu-1 shHSPD1 \#48

\section{Calu-1}

$$
\text { pLKO }
$$

shHSPD1 \#48

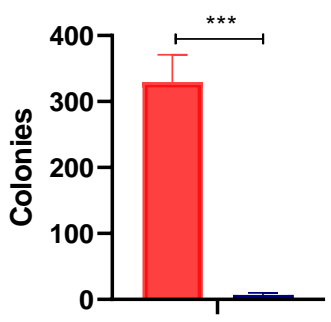

E

Calu-1 pLKO

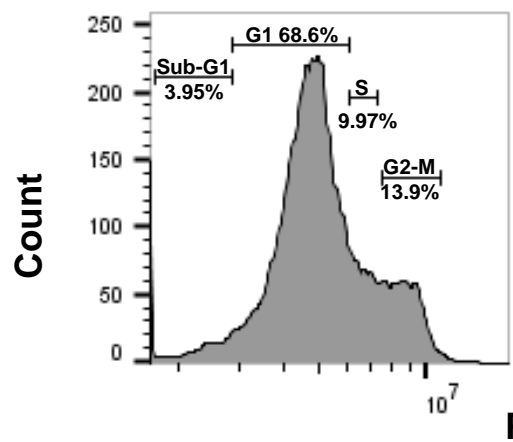

Calu-1 shHSPD1 \#48

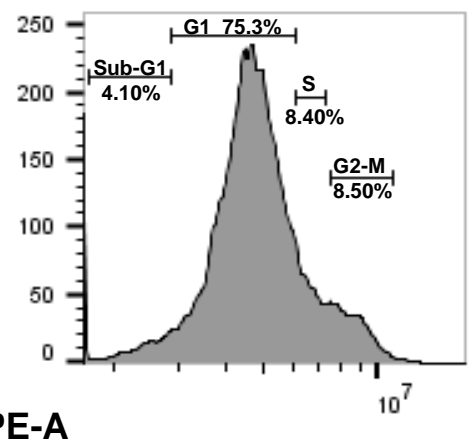

F

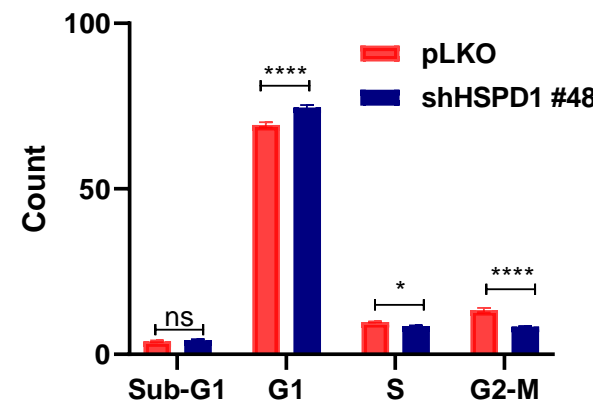




\section{Supplementary Figure 2}

A

H23 (ADC)

SK-MES-1 (SqCC)
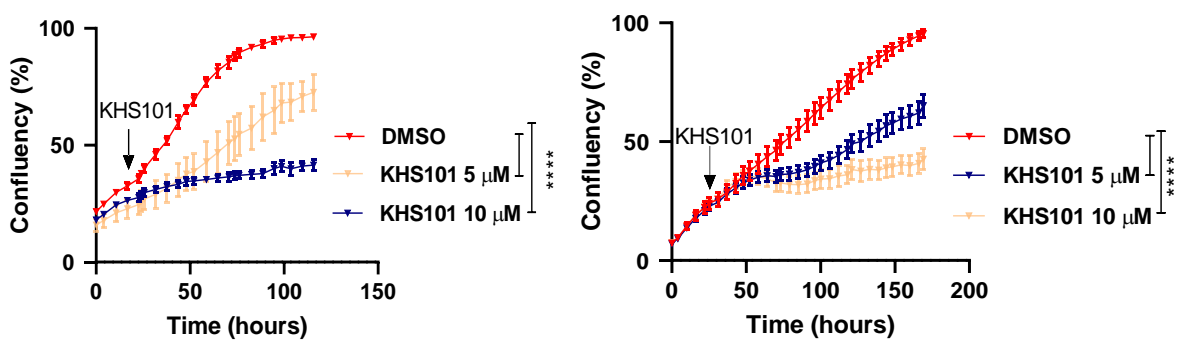

B

A549

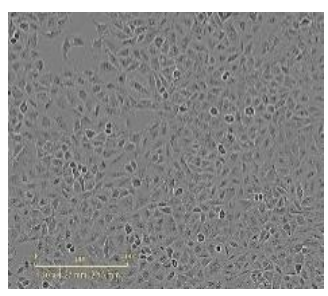

DMSO

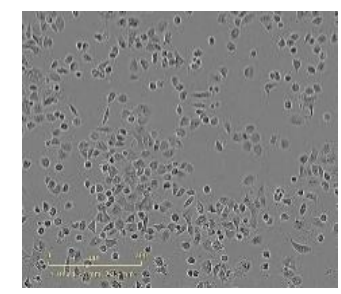

KHS101 $10 \mu \mathrm{M}$

H1299

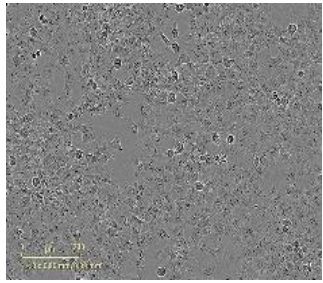

DMSO

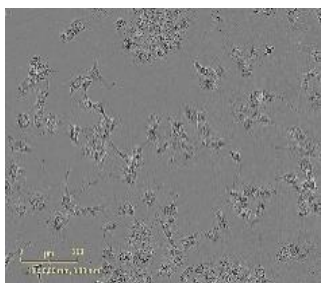

KHS101 $10 \mu \mathrm{M}$
H23

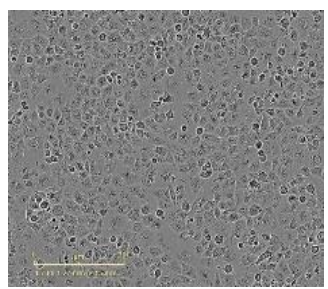

DMSO

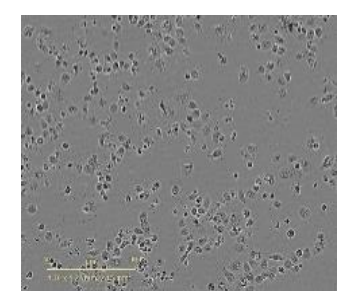

KHS101 $10 \mu \mathrm{M}$

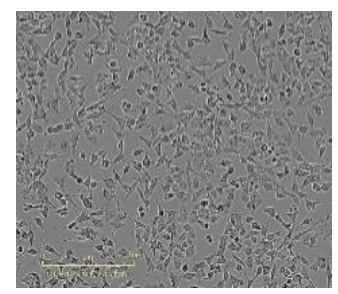

DMSO

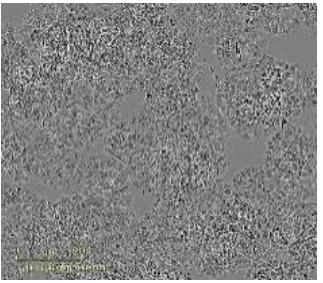

DMSO
H460

Calu-1

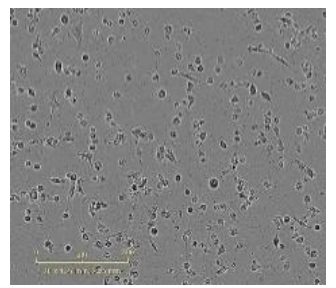

KHS101 $10 \mu \mathrm{M}$

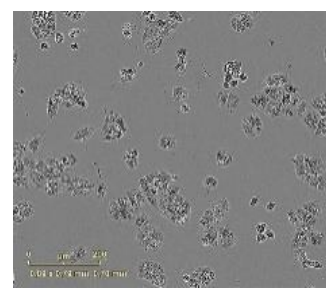

KHS101 $10 \mu \mathrm{M}$

SK-MES-1

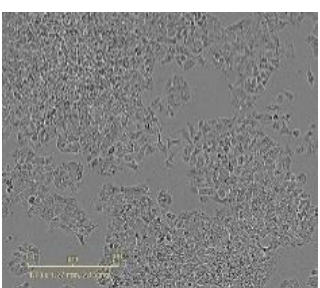

DMSO

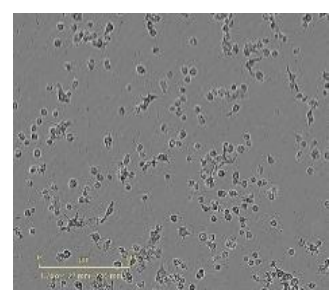

KHS101 $10 \mu M$ 


\section{Supplementary Figure 3}

A

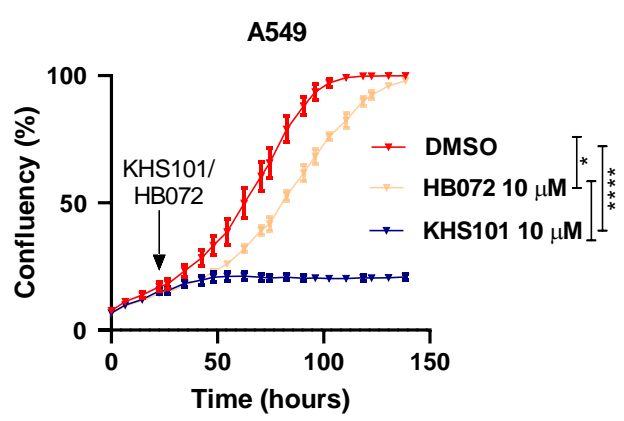

B

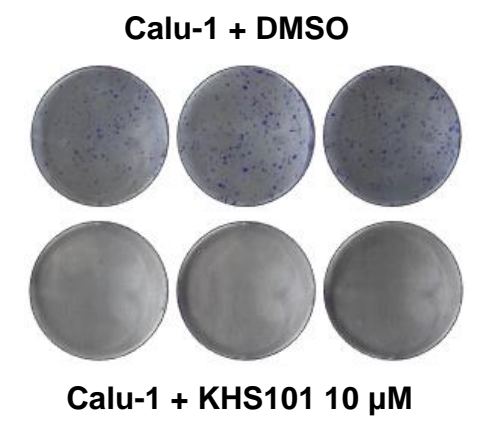

Calu-1

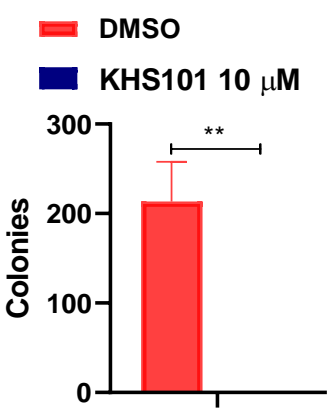

C
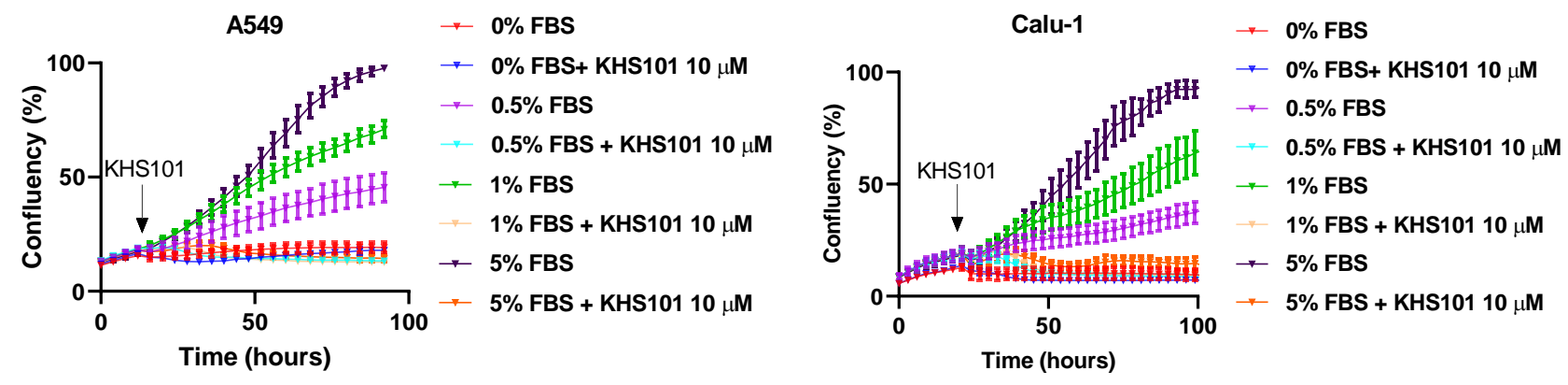


\section{Supplementary Figure 4}

A

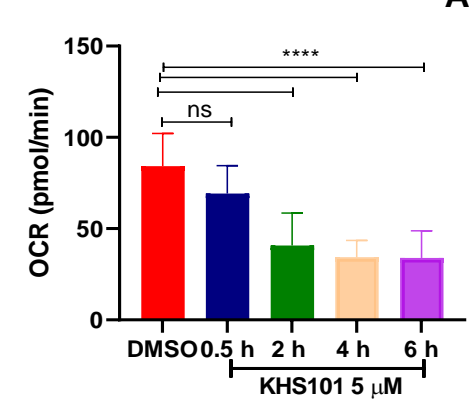

Basal respitation
A549

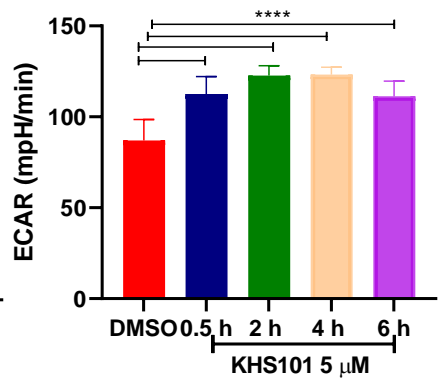

Indicative glycolysis

B

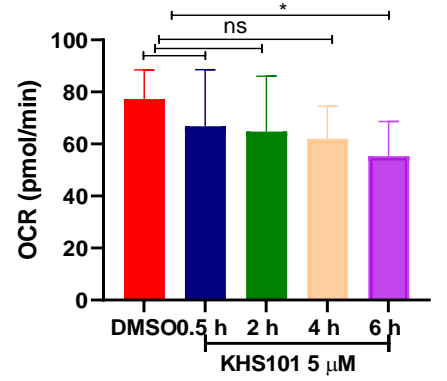

Basal respitation
Calu-1

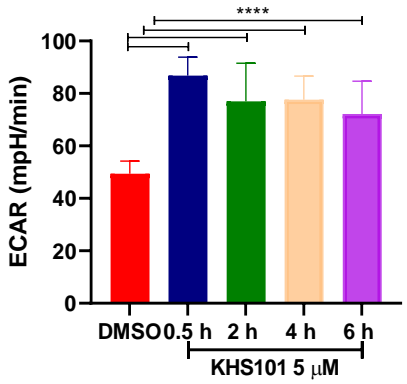

Indicative glycolysis
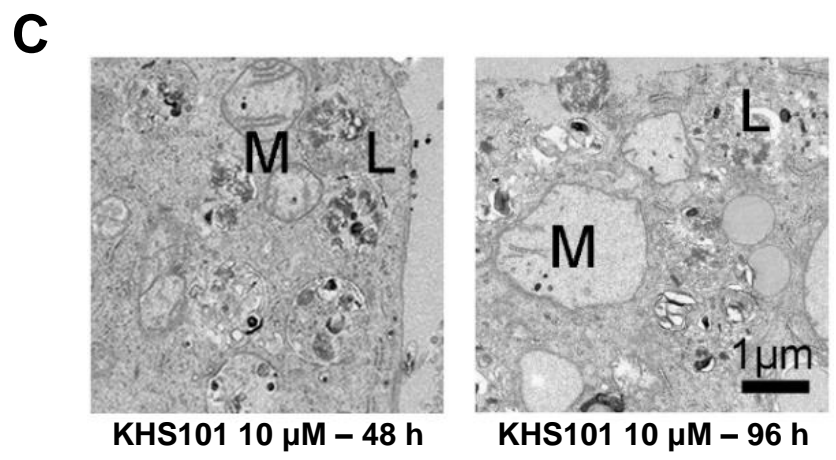

D

Calu-1

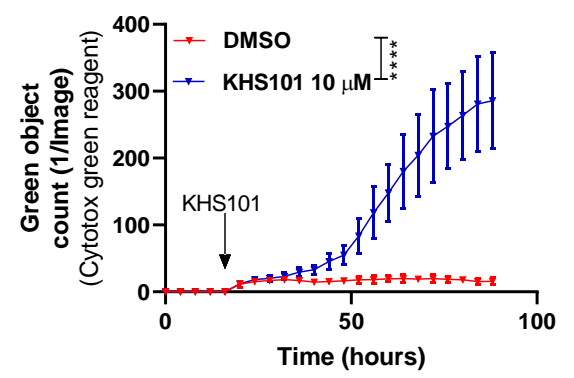

E

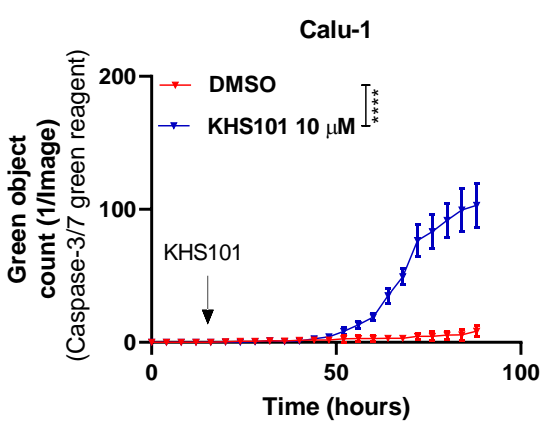

F

G

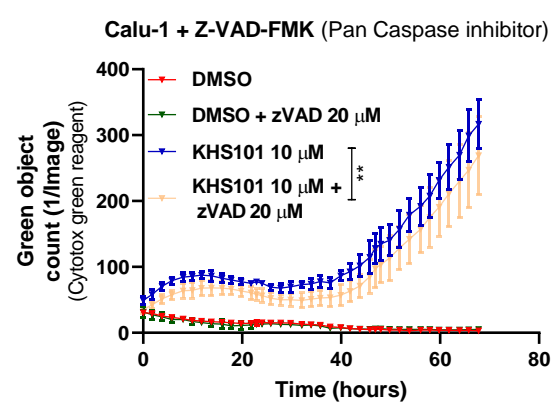

A549

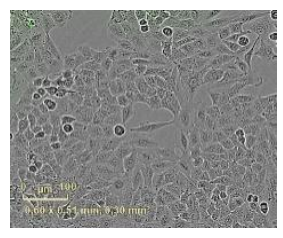

DMSO

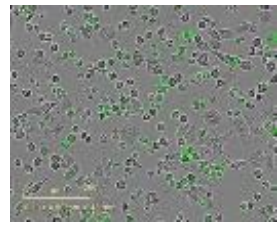

KHS101 $10 \mu \mathrm{M}$

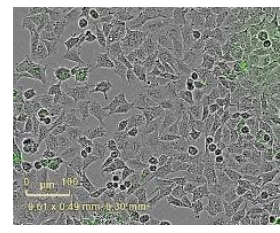

DMSO
Calu-1

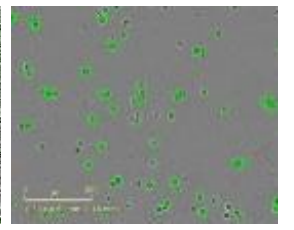

KHS101 $10 \mu \mathrm{M}$

H
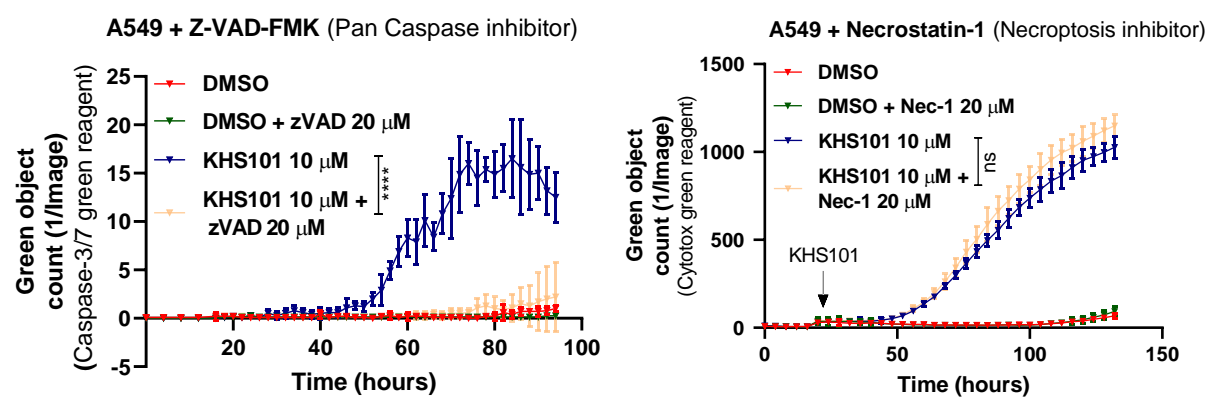

J

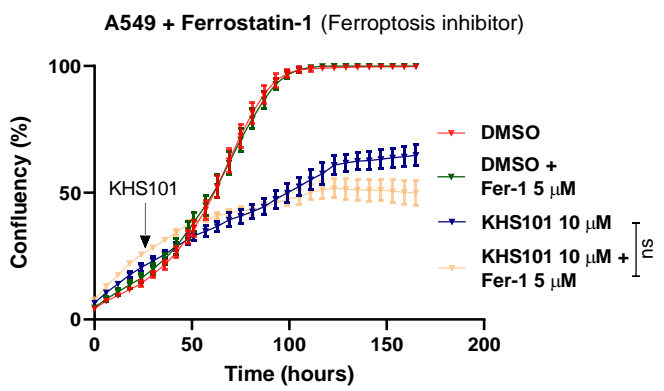


(which was not certified by peer review) is the author/funder, who has granted bioRxiv a license to display the preprint in perpetuity. It is m

\section{Supplementary Figure 5}

A

LL2 (mouse)

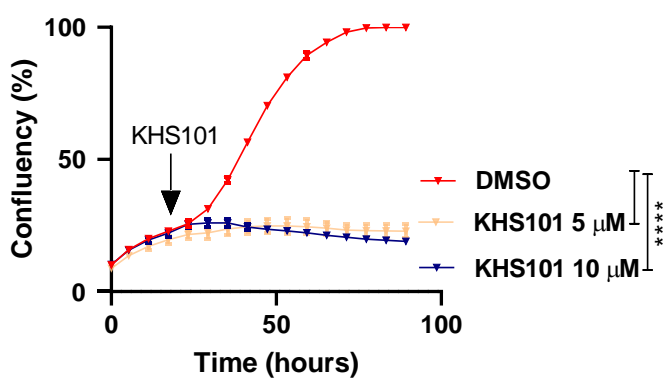

C

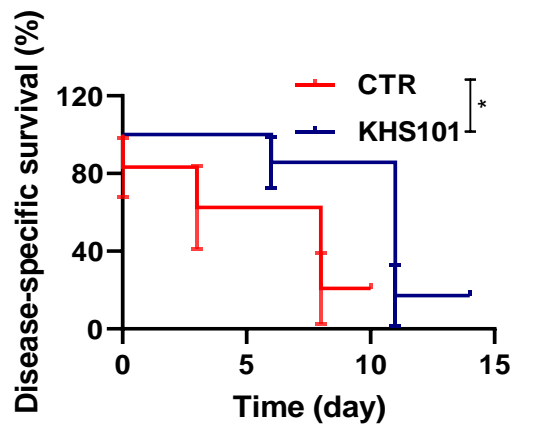

B

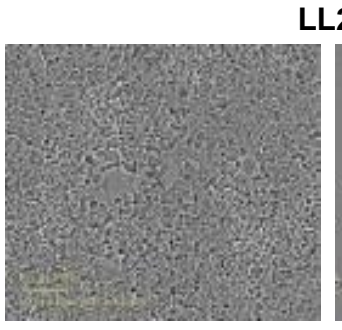

DMSO
LL2

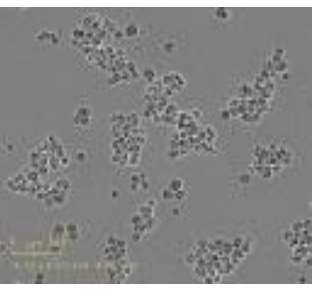

KHS101 $10 \mu \mathrm{M}$
D

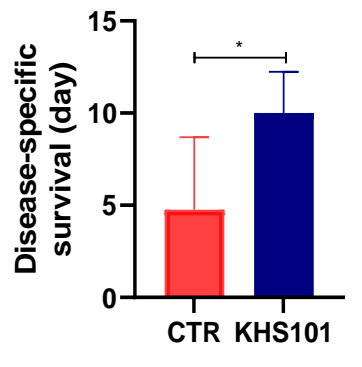




\section{Supplementary Figure 6}

A

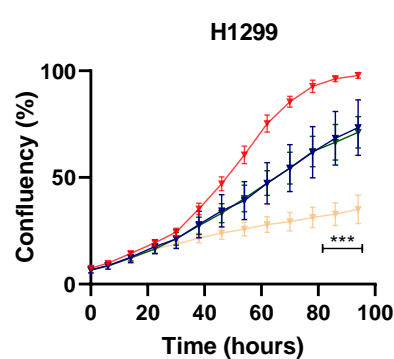

- DMSO + 0.9\% NaCl $\rightarrow$ Cisplatin $4 \mu \mathrm{M}$

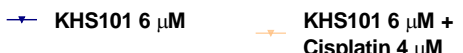

B

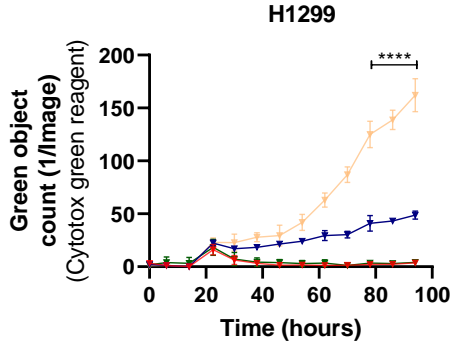

C

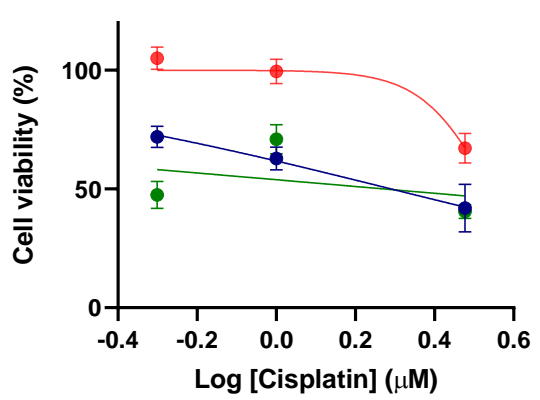

- A549 $\longrightarrow \mathrm{IC}_{50}=3.46$

$\longrightarrow \mathrm{A} 549+\mathrm{KHS} 1015 \mu \mathrm{M} \longrightarrow \mathrm{IC}_{50}=1.95$

$\rightarrow A 549+\mathrm{KHS} 1013 \mu \mathrm{M} \longrightarrow \mathrm{IC}_{50}=1.87$
H460

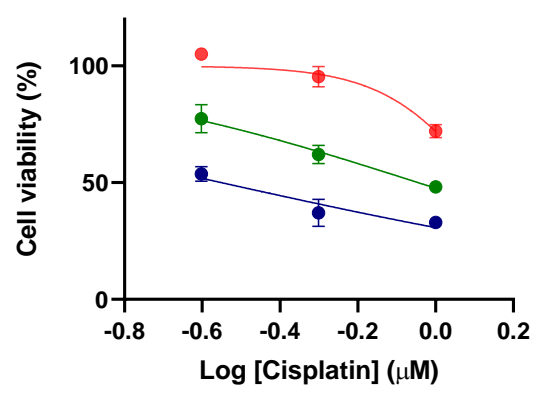

$\rightarrow \mathrm{H} 460 \longrightarrow \mathrm{IC}_{50}=1.32$

- $\mathrm{H} 460+\mathrm{KHS} 1013 \mu \mathrm{M} \longrightarrow \mathrm{IC}_{50}=0.28$

$-\mathrm{H} 460+\mathrm{KHS} 1011 \mu \mathrm{M} \longrightarrow \mathrm{IC}_{50}=0.90$
H1299

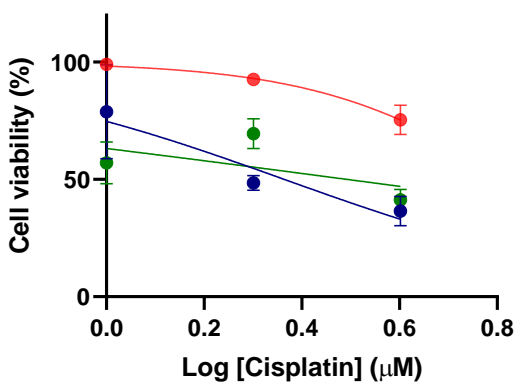

- $\mathrm{H} 1299 \longrightarrow \mathrm{IC}_{50}=6.76$

- $\mathrm{H} 1299+6 \mu \mathrm{M} \mathrm{KHS101} \longrightarrow \mathrm{IC}_{50}=2.31$

$\longrightarrow \mathrm{H} 1299+3 \mu \mathrm{M}$ KHS101 $\longrightarrow \mathrm{IC}_{50}=3.11$ 


\section{Supplementary Figure 8}

(which was not certified by peer review) is the author/funder, who has granted bioRxiv a license to display the preprint in perpetuity. It is m available under aCC-BY-NC-ND 4.0 International license.

A

B

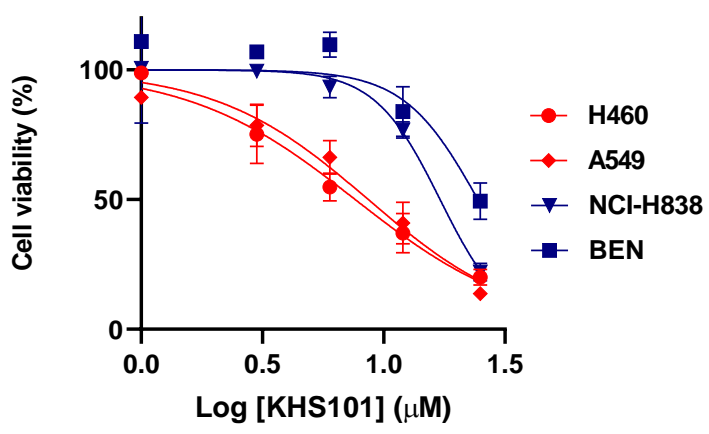

Up-regulated genes in resistant cell lines

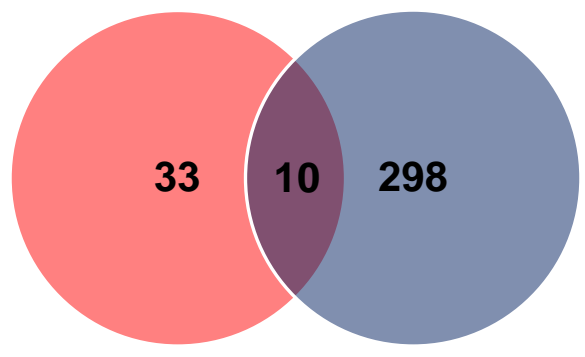

Trascriptome analysis $I_{50}$ correlation (4-fold) $(r>0.5)$

C

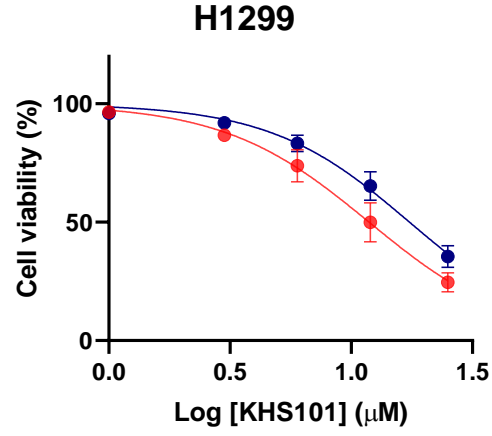

$-\mathrm{H} 1299$ Empty $\rightarrow \mathrm{IC}_{50}=11.85$
$-\mathrm{H} 1299$ NLRC5 $\rightarrow \mathrm{IC}_{50}=17.39$$I^{*}$
Down-regulated genes in resistant cell lines

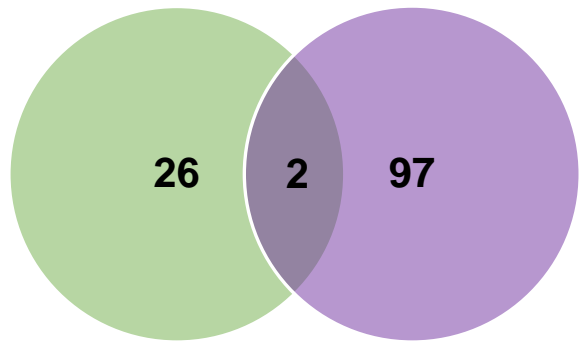

Trascriptome analysis $\mathrm{IC}_{50}$ correlation (4-fold)

$(r<-0.5)$

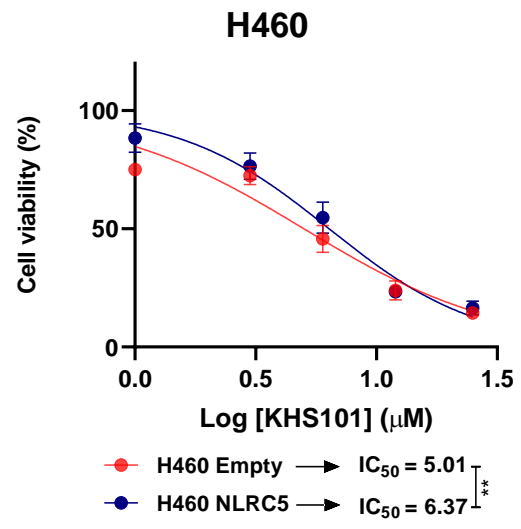




\section{SUPPLEMENTARY LEGENDS}

Suppl. Figure 1 A) Western blot analysis of HSPD1 protein level in SK-MES-1 and Calu-1 cells upon infection with respectively 5 or 3 independent shRNAs (\#44, \#45 \#46, \#47 and \#48) targeting HSPD1 compared to scramble-infected cells (pLKO). $\beta$-Actin was used as loading control. B) Real-time proliferation curves of SK-MES-1 and Calu-1 infected with non-targeting pLKO or shHSPD1. Plotted is cells' confluency over time. P-values are from two-way ANOVA. Points $(n=5)$ are average $\pm S D .{ }^{* * * *}<0.0001$. Colony formation of H460 (C) and Calu-1 (D) cells infected with pLKO or shHSPD1, stained with crystal-violet and quantified in triplicates. Scale bars are average \pm SD. P-values are from unpaired $t$-test. ${ }^{* *}<0.01,{ }^{* * *}<0.001$.

E) FACS plots of Calu-1 cells infected with pLKO or shHSPD1 and stained with PI for cell cycle analysis.

F) Bar graph showing the \% of cells in each cell cycle phase of Calu-1 cells upon infection with pLKO or shHSPD1. P-values are from two-way ANOVA. Scale bars $(n=3)$ are average $\pm S D .{ }^{*}<0.05,{ }^{* \star * *}<0.0001$.

Suppl. Figure 2 A) Real-time proliferation curves of H23 and SK-MES-1 treated either with vehicle (DMSO) or KHS101. P-values are from two-way ANOVA. Points $(n=5)$ are average $\pm S D$. ${ }^{* * *}<0.0001$. B) Images of cells (A549, Calu-1, H1299, H460, H23 and SK-MES-1) treated with DMSO or KHS101 $10 \mu \mathrm{M}$ (after 5 days of treatment).

Suppl. Figure 3 A) Real-time proliferation curves of A549 cells treated either with KHS101 or with the corresponding inactive KHS101 analog (HB072) compared to vehicle-treated cells. Points $(n=5)$ are average \pm SD. P-values are from two-way ANOVA. ${ }^{*}<0.05,{ }^{* \star * *}<0.0001$. B) Colony formation of Calu- 1 treated for 5 days with KHS101 or vehicle and then left to grow in drug-free media, stained with crystalviolet and quantified in triplicates. Scale bars are average \pm SD. P-values are from unpaired $t$-test. ${ }^{* *}<0.01$.

C) Real-time proliferation curves of A549 and Calu-1 treated with KHS101 in presence of different concentration of FBS in the media. Points $(n=5)$ are average \pm SD.

Suppl. Figure 4 Quantification of OCR (basal respiration) and ECAR (indicative glycolysis) of A549 (A) and Calu-1 (B) cells treated for $0.5 \mathrm{~h}, 2 \mathrm{~h}, 4 \mathrm{~h}$ and $6 \mathrm{~h}$ compared to control cells. Bars $(n=5)$ are average \pm SD. P-values are from unpaired $t$-test. ${ }^{*}<0.05,{ }^{* * * *}<0.0001$. C) Electron microscopy images of A549 treated either for 48 or 96 hours with KHS101 $10 \mu \mathrm{M}$. L-lysosomes, M-mitochondria. Dead cell quantification as green object count using Cytotox green reagent (D) or caspse-3/7 reagent (E) of vehicle or KHS101 treated Calu-1 cells. F) Images of A549 and Calu-1 cells treated with vehicle or KHS101 and stained with caspase$3 / 7$ reagent. G) Dead cell quantification as green object count of Calu-1 treated either with DMSO or KHS101 in combination with pan-caspase inhibitor Z-VAD-FMK. H) Dead cell quantification as green object count using caspase3/7 green reagent of A549 treated either with DMSO or KHS101 in combination with pan caspase inhibitor Z-VAD-FMK. I) Dead cell quantification as green object count of A549 treated either with DMSO or KHS101 in combination with necroptosis inhibitor Necrostatin-1. J) Real-time proliferation curves of A549 treated either with DMSO or KHS101 in presence of ferroptosis inhibitor Ferrostatin-1. In D, $E, G, H, I$ and J points $(n=5)$ are average \pm SD. P-values are from two-way ANOVA. ${ }^{* *}<0.01,{ }^{* * * *}<0.0001$. 
Suppl. Figure 5 A) Real-time proliferation curves of mouse cell lines LL2 treated either with vehicle (DMSO) or KHS101. Points $(n=5)$ are average \pm SD. P-values are from two-way ANOVA. ${ }^{* * *}<0.0001$. B) Images of Ladi3.1 and LL2 treated with DMSO or KHS101 $10 \mu \mathrm{M}$. C) Kaplan-Meier disease-specific survival analysis of C57BL/6 mice treated with $6 \mathrm{mg} / \mathrm{kg} \mathrm{KHS101}$ or vehicle (5\% (v/v) Ethanol - 15\% (w/v) Captisol solution) for 2 weeks. P-value is Log-rank test. ${ }^{*}<0.05$. Disease-specific survival time (shown on the right panel) is calculated starting from the first appearance of bioluminescence. Bars are average \pm SD. P-value is unpaired $t$-test. * $<0.05$.

Suppl. Figure 6 Real-time proliferation curves (A) and dead cell quantification (B) of H1299 cells treated with KHS101 and/or cisplatin at indicated doses compared to control cells. Points $(n=5)$ are average \pm SD. P-value are from two-way ANOVA. ${ }^{* * *}<0.001,{ }^{* * * *}<0.0001$.C) Dose-response curves to cisplatin of A549, $\mathrm{H} 460$ and H1299 cells treated with different concentration of KHS101. IC 50 values $(\mu M)$ are shown. Points $(n=5)$ are average \pm SD.

Suppl. Figure 7 A) Dose-response curves (normalized to DMSO control) to KHS101 of the remaining 24 NSCLC cell lines belonging to CL-100 ProLiFiler screening. Points are average \pm SD. Their $I_{50}$ values $(\mu \mathrm{M})$ are shown with $95 \%$ confidence intervals.

Suppl. Figure 8 A) Dose-response curves of 4 cell lines (H460, A549, NCl-H838 and BEN) as validation of the CL-100 ProLiFiler screening. Points $(n=5)$ are average \pm SD B) Venn diagrams showing overlap of up- or down-regulated genes in resistant cells identified in the transcriptome analysis and $\mathrm{IC}_{50}$ correlation analysis. C) Dose-response curves (normalized to DMSO control) of H1299 and H460 overexpressing NLRC5 compared to empty control cells. Points $(n=4)$ are average $\pm S D$. IC 50 values $(\mu M)$ are shown. Pvalue is from two-way ANOVA. ${ }^{* *}<0.01$.

\section{SUPPLEMENTARY METHODS}

\section{Lentiviral transduction}

Plasmids for HSPD1 knock down (TRCN0000029444, TRCN0000029445, TRCN0000029446, TRCN0000029447 and TRCN0000029448 for human cell lines) are from Sigma. Scrambled pLKO.1 (referred to as PLKO) was used as non-targeting control. NLRC5 expression vector (EX-A3335-Lv105) and control vector (Ex-Neg-LV105b) are from GeneCopoeia. Plasmids containing RNAs for COX5B (gRNA sequence \#1 is ACTTCGCGGAGCTGGAACGC; gRNA sequence \#2 is CAGCCAAAACCAGACGACGC) and SLC6A8 (gRNA sequence \#2 is ACGGGGCCGTCGCCCTTGGC; gRNA sequence \#3 is GCCCTTACCATGCAGACCAG) knock-out (pLENTI-CRISPR-V2) are from Genscript. For production of lentiviral particles, 293T cells were transfected with $8 \mu \mathrm{g}$ knock-down/expression vectors and $2 \mu \mathrm{g}$ of packaging vectors (pMDL, pVsVg and pRevRes) in complex with $24 \mu \mathrm{PEI}$ (Polysciences) in $0.9 \% \mathrm{NaCl}$. After 48 hours, supernatant was collected, centrifuged and filtered. For transduction, 150,000 cells were 
seeded in a 6-well plate and infected in presence of $8 \mu \mathrm{g} / \mathrm{mL}$ polybrene (Sigma). Selection was done with $3 \mu \mathrm{g} / \mathrm{mL}$ puromycin (Sigma) and cells were maintained in $1 \mu \mathrm{g} / \mathrm{mL}$ puromycin.

\section{Western blot analysis}

For proteins isolation, cells were lysed in RIPA buffer and quantified using Pierce BCA kit (Thermo-Fisher). For cytosolic/mitochondrial fractionation Cytochrome c Release Assay Kit (abcam, ab65311) was used. Proteins lysates $(10-20 \mu \mathrm{g})$ were resolved on 5\%-12\% SDS-PAGE gels and transferred to PVDF membrane (Thermo-Fisher). Membranes were blocked in 5\% Milk (BioRad) or 5\% BSA (Sigma) in 1X TBST and incubated overnight at $4^{\circ} \mathrm{C}$ in primary antibodies. Membranes were then washed with $1 \mathrm{X}$ TBST and incubated with secondary antibodies (Southern Biotech) for 1 hour. The membranes were developed with ECL reagent (Thermo Fisher) on to X-ray films (Thermo-Fisher) using the chemiluminescence imager, AGFA CP100. Rabbit anti-HSPD1 (ab46798, 1:20000) and rabbit anti-NLRC5 (ab117624, 1:1000) antibodies were purchased from Abcam; mouse anti-TOMM20 (H00009804-M01, 1:1000) was purchased from Abnova; anti- $\beta$-Actin (8H10D10) HRP conjugate (1:10000) was purchased from Cell Signaling

\section{Colony formation assay}

To assess clonogenic ability of knockdown cells or KHS101 treated cells, a colony formation assay was performed. Control (pLKO) and knockdown cells were plated in triplicates at a low density (1,500 cells/well) in a 6-well plate in triplicates and they were allowed to grow until they formed visible colonies. To assess, instead, the clonogenic ability upon KHS101 treatment, 200,000 cells were seeded in triplicates in 6-well plates and then treated with $10 \mu \mathrm{M}$ KHS101 for 5 days. For KHS101 treated cells the media was replaced with normal media, whereas the DMSO cells where collected, counted and seeded in triplicates at low density (1,500 cells/well) and they were allowed to grow until they formed visible colonies. Cells were washed with 1 X PBS and fixed in 10\% formalin (Sigma) for 5 minutes. After washing, colonies were stained with $0.05 \%$ crystal violet solution (Biomatik, CAS 548629) for 30 minutes and washed twice with deionized water. Colonies were photographed and counted.

\section{FACS analysis}

Cell cycle analysis was performed using the Propidium iodide (PI; Sigma) staining. 50,000 cells were seeded in triplicates in 12-well plates and incubated overnight. Samples were prepared as described in (51). For ROS staining, 50,000 cells were seeded in 12-well plates and the day after they were treated with KHS101 in combination with cisplatin. After 24 hours, samples were washed and stained for 30 minutes at $37^{\circ} \mathrm{C}$ with CM-H2DCFDA $5 \mu \mathrm{M}$ (Thermo Fisher, C6827). Then they were collected in FACS tubes, washed and re-suspended in FACS buffer (2\% FBS, 5 mM EDTA in 1X PBS). Samples were run on Cytoflex FACS machine (Beckman) and data were analyzed using FlowJo software v10.6.

\section{Immunohistochemistry (IHC)}


HSP60 (HSPD1) immunohistochemistry was performed on 20 consecutive NSCLC lung surgical specimens using an automated platform (BenchMark, Ventana Medical Systems, Roche, Basel, Switzerland). Briefly, samples were pretreated for 36 minutes with antigen retrieval ULTRA CC1 then they were incubated for 32 minutes at $36^{\circ} \mathrm{C}$ with HSP60 (HSPD1) (AbTA800758, Clone OTI3A2, 1:100 dilution, ORIGENE, Rockville, US) primary antibody. The use of retrospective LC tissues for immunohistochemical study was approved by the Research Ethics Committee of the San Luigi Hospital/University of Turin (approval n.26 dated January $18^{\text {th }}$ 2019). Informed consent was obtained from all patients. Samples have been anonymized by a staff member not involved in the study and all patient information are made unavailable to the investigators.

\section{Generation of CRISPR/Cas9 lentiviral library and CRISPR screen}

CRISPR/Cas9 lentival library was generated as described in (25). A549 Cas9 cells were transduced with serial dilutions of a virus to find the $\mathrm{MOI}$ of $\sim 0.3$. A549 Cas9 cells were transduced with lentiviral Human GeCKO v2 knockout pooled library part A and part B (a gift from Feng Zhang (52), Addgene \# 1000000049) at $\mathrm{MOI}$ of 0.3 in the presence of $10 \mu \mathrm{g} / \mathrm{mL}$ of polybrene for 24 hours, then replaced the virus medium with fresh growth medium and continued to culture the cells for 48 hours. The cells were selected with $50 \mu \mathrm{g} / \mathrm{mL}$ of puromycin for 3 days. Then 4 million cells were seeded in 10-cm dishes and treated the day after either with vehicle or with 15/10 $\mu \mathrm{M}$ KHS101. A549 Cas9 pLKO were used as positive control. After 2 weeks, the media containing the drug was replaced with normal media to allow the cells to grow again. 40 million cells were then collected for genomic DNA isolation. Next generation sequencing was performed on the Illumina HiSeq 2500 platform in Deep Sequencing Facility of TU Dresden. The raw FASTQ files were analyzed with MAGeCK-VISPR (53).

\section{Genomic DNA isolation and PCR amplification}

Genomic DNA was extracted with NucleoSpin® Blood XL (Machery Nagel \# 740950.50) according to the manufacturer's protocol. The first round PCR of Next Generation Sequence (NGS) is performed with 26 separate $100 \mu \mathrm{L}$ redundant reactions, each containing $5 \mu \mathrm{g}$ of DNA, $50 \mu \mathrm{L}$ Q5尺 Hot Start High-Fidelity $2 X$ Master Mix (NEB \# M0494L), and $3 \mu \mathrm{L}$ of a $10 \mu \mathrm{M}$ solution of each primer (P5 and P7). The PCR was performed as described in (25).

\section{Transmission electron microscopy}

A549 cells were treated either with vehicle (DMSO) or KHS101 $10 \mu \mathrm{M}$ for 48 and 96 hours. After treatment the cells were fixed with $2 \%$ glutaraldehyde in $0.04 \mathrm{M}$ phosphate buffer $\mathrm{pH} 7.4$ for 60 minutes, scraped off, collected in a tube and post-fixed with the same fixative for 24 hours. The cells were then washed in PBS and resuspended in $15 \%$ BSA for 10 minutes. The cells were centrifuged and the cell pellet fixed by slowly adding the fixative for 48 hours at $4^{\circ} \mathrm{C}$. The cell pellets were cut in smaller pieces and prepared for EM like following. Pellet fragments were washed in phosphate buffer, stained with $1 \%$ osmium tetraoxide in 
phosphate buffer for 90 minutes, dehydrated in ethanol series and acetone and embedded in TAAB 812 Embedding Resin (T030, TAAB). Semithin $(1 \mu \mathrm{m})$ sections were cut on Leica Ultracut UCT microtome and stained with toluidine blue. Ultrathin $(70 \mathrm{~nm})$ sections were collected on uncoated nickel grids (M200-NI, Electron Microscope Sciences). The grids were stained with $3 \%$ uranyl acetate for 15 minutes at $60^{\circ} \mathrm{C}$ and $3 \%$ lead citrate (Leica Ultrostain 2) for 6 minutes at RT. The sections were analyzed with JEM-1400 Plus electron microscope, equipped with Quemsa TEM CCD camera and images obtained using Radius software (TEM Imaging Platform software).

\section{Survival analysis}

Normalized gene expression value for HSPD1 was obtained for lung cancer patient samples from GEO (GSE30219) and mRNA z-score values for the TCGA profile (TCGA LUAD, Cell 2018) from cbioportal platform. Survival curves were generated using Kaplan-Meier estimate with the samples categorized into low- and high-HSPD1 groups based on the median of the HSPD1 gene expression value. Log-rank test was conducted to obtain the significance between the two groups in $\mathrm{R}$ software.

\section{Differential gene expression analysis and correlation.}

Differential gene expression (DGE) analysis was performed between the KHS101-sensitive and KHS101resistant cell lines identified from the drug sensitivity analysis. Briefly, the top four $\mathrm{KHS101-sensitive} \mathrm{(NCl-}$ H460, NCl-H1581, LOU-NH91 and A549) and KHS101-resistant (SK-LU-1, NCl-H1563, BEN and NClH838) cell lines were chosen for the analysis. Differential expression between the sensitive and resistant groups was performed using CCLE gene expression profile (GSE36133) with RMA $\log _{2}$ signal intensity using GEO2R package in GEO with a moderated t-test parameter. 33 up-regulated and 26 down-regulated genes were fileted with a $p$-value of $<0.05$ and $\log _{2}$ fold change cutoff of 2 . In parallel, Pearson's correlation analysis was performed between 21 cell lines $\mathrm{IC}_{50}$ values of $\mathrm{KHS} 101$ and 18,569 genes expression from CCLE. With a correlation value of 0.5 and $p$-value $<0.05,298$ positively and 97 negatively correlated genes were filtered. Then, an overlap analysis was performed with the DGEs list and correlation list to identify a stringent gene list of 12 genes. Correlation analysis between HSPD1 gene expression value obtained from GEO (GSE47206) and KHS101 dose response IC $_{50}$ values was performed in GraphPad Prism 8.

\section{Differential metabolite analysis}

Similar to the differential gene expression analysis, a differential metabolite analysis was performed for the top four KHS101-sensitive and KHS101-resistant group cell lines with the information of $225 \log _{10}$ normalized quantitative metabolites levels across 177 CCLE cell lines (33). 7 differential metabolites were identified with a $\log _{10}$ fold change of 2 and $p$-value $<0.05$.

\section{Gene ontology analysis}


Gene ontology analysis was performed for the top 20 gene candidates identified from a global CRISPR knockout screen and with treatment using KHS101 drug. Genes were assessed for the enrichment using GO cellular component 2017b in Enrichr (54).

\section{Fitness gene and cancer gene dependency}

HSPD1 fitness was analyzed as described in (28). HSPD1 gene's cancer dependency was analyzed in a panel of non-small cell lung cancer cell lines $(n=52)$ from PROJECTDRIVE RNAi screen (27). Using RSA gene level metric of threshold -3 , the essentiality of the gene in cell lines was determined.

\section{In vivo experiments}

NSG strain (JAX) was used as experimental model to study the tumor growth of HSPD1 knockdown cells (A549 and $\mathrm{H} 1299$ ). For subcutaneous injections, $0.5 \times 10^{6}$ cells re-suspended in $50 \mu \mathrm{L} 0.9 \% \mathrm{NaCl}$ were mixed with Matrigel (Corning) in a ratio 1:1 (v:v). Cells were injected in flanks of 9-15-weeks-old NSG with 8 mice per group. Caliper measurements were taken twice a week and tumor volume was calculated using the formula (Length $\times$ Width $2 \times \pi$ ) $/ 6$. After $4 / 5$ weeks, mice were euthanized by cervical dislocation and tumors were isolated and weighted.

C57BL/6 strain was used as experimental model to evaluate KHS101 effect on lung metastasis tumor formation. For tail-vein metastasis assay, $0.5 \times 10^{6} \mathrm{LL} 2$ cells were re-suspended in $100 \mu \mathrm{l} \mathrm{PBS}$ and injected in the tail vein of female C57BL/6, with 10 mice per group. After 2 weeks either vehicle $(5 \%(\mathrm{v} / \mathrm{v})$ Ethanol $15 \%$ (w/v) (2-Hydroxypropyl)- $\beta$-cyclo-dextrin (Captisol Technology)) or $6 \mathrm{mg} / \mathrm{kg} \mathrm{KHS101}$ (Cellagen Technology) were injected twice a day subcutaneously for 10 days. Lung metastases were monitored by bioluminescence imaging (BLI). Anesthetized mice were intraperitoneally injected with $50 \mathrm{mg} / \mathrm{mL}$ D-luciferin (Kayman Chemicals). Bioluminescence images were acquired with Lumina III in vivo Imaging System (IVIS, Perkin Elmer). Time of survival with disease was calculated as difference between the day of death and the day of appearance of the bioluminescence signal.

In vivo experiments were performed by skilled experimenters trained according to FELASA guidelines. Animal protocols were approved by the Institutional Animal Care and Use Committee of the Regierung von Unterfranken. 


\section{Supplementary Table 1}

\begin{tabular}{|c|c|}
\hline \multicolumn{2}{|c|}{ CL-100 ProLiFiler screening } \\
\hline Cell line & Medium \\
\hline A549 & DMEM + 10\% FCS \\
\hline BEN & DMEM + 10\% FCS \\
\hline COR-L279 & RPMI-1640+10\% FCS \\
\hline DV90 & RPMI- $1640+10 \%$ FCS \\
\hline EPLC-272H & RPMI-1640+10\% FCS \\
\hline H1299 & DMEM + 10\% FCS \\
\hline $\mathrm{H} 460$ & DMEM + 10\% FCS \\
\hline HCC827 & RPMI-1640+10\% FCS \\
\hline LOU-NH91 & RPMI-1640+10\% FCS \\
\hline $\mathrm{NCl}-\mathrm{H} 1048$ & RPMI- $1640+10 \%$ FCS \\
\hline $\mathrm{NCl}-\mathrm{H} 1437$ & RPMI- $1640+10 \%$ FCS \\
\hline $\mathrm{NCl}-\mathrm{H} 1563$ & RPMI-1640+10\% FCS \\
\hline $\mathrm{NCl}-\mathrm{H} 1573$ & RPMI-1640+10\% FCS \\
\hline $\mathrm{NCl}-\mathrm{H} 1581$ & RPMI- $1640+10 \%$ FCS \\
\hline $\mathrm{NCl}-\mathrm{H} 1703$ & RPMI-1640 + 10\% FCS \\
\hline $\mathrm{NCl}-\mathrm{H} 1838$ & RPMI-1640+10\% FCS \\
\hline $\mathrm{NCl}-\mathrm{H} 2009$ & RPMI-1640+10\% FCS \\
\hline $\mathrm{NCl}-\mathrm{H} 2110$ & RPMI-1640 + 10\% FCS \\
\hline $\mathrm{NCl}-\mathrm{H} 2286$ & RPMI-1640+10\% FCS \\
\hline $\mathrm{NCl}-\mathrm{H} 292$ & RPMI-1640+10\% FCS \\
\hline $\mathrm{NCl}-\mathrm{H} 441$ & RPMI-1640+10\% FCS \\
\hline $\mathrm{NCl}-\mathrm{H} 838$ & RPMI-1640 + 10\% FCS \\
\hline RERF-LC-Ad2 & RPMI-1640+10\% FCS \\
\hline RERF-LC-MS & RPMI- $1640+10 \%$ FCS \\
\hline SCLC-21H & DMEM + 10\% FCS \\
\hline SK-LU-1 & DMEM + 10\% FCS \\
\hline
\end{tabular}




\section{Supplementary Table 2}

\begin{tabular}{|c|c|}
\hline \multicolumn{2}{|c|}{$\begin{array}{l}\text { HSPD1 sensitivity score from } \\
\text { PROJECTDRIVE }\end{array}$} \\
\hline Cell line & Sensitivity Score \\
\hline $\mathrm{NCIH} 1568$ & -11.94 \\
\hline $\mathrm{NCIH} 1944$ & -11.06 \\
\hline CALU6 & -10.19 \\
\hline $\mathrm{NCIH} 1437$ & -10.18 \\
\hline $\mathrm{NClH} 1299$ & -9.45 \\
\hline $\mathrm{NClH} 2172$ & -9.44 \\
\hline $\mathrm{NClH} 1355$ & -8.68 \\
\hline $\mathrm{NCIH} 23$ & -8.61 \\
\hline HCC15 & -8.45 \\
\hline $\mathrm{NClH} 1793$ & -8.29 \\
\hline KNS62 & -7.59 \\
\hline HCC1359 & -6.82 \\
\hline $\mathrm{NCIH} 441$ & -6.63 \\
\hline $\mathrm{NCIH} 358$ & -6.52 \\
\hline EBC1 & -6.44 \\
\hline $\mathrm{NClH} 1703$ & -6.15 \\
\hline $\mathrm{ABC1}$ & -6.10 \\
\hline $\mathrm{NCIH} 2030$ & -6.03 \\
\hline CORL23 & -5.76 \\
\hline RERFLCMS & -5.65 \\
\hline HCC4006 & -5.25 \\
\hline $\mathrm{NCIH} 2110$ & -5.18 \\
\hline A549 & -4.47 \\
\hline SQ1 & -4.40 \\
\hline $\mathrm{NCIH} 522$ & -4.20 \\
\hline $\mathrm{HCC} 44$ & -4.17 \\
\hline $\mathrm{NClH} 2170$ & -4.16 \\
\hline $\mathrm{NClH} 1693$ & -4.02 \\
\hline $\mathrm{NClH} 661$ & -4.01 \\
\hline $\mathrm{NClH} 1792$ & -3.97 \\
\hline $\mathrm{NClH} 1373$ & -3.74 \\
\hline $\mathrm{NClH} 460$ & -3.66 \\
\hline $\mathrm{NClH} 2122$ & -3.64 \\
\hline $\mathrm{NClH} 2009$ & -3.63 \\
\hline LCLC103H & -3.63 \\
\hline SW1573 & -3.43 \\
\hline $\mathrm{NClH} 1975$ & -3.23 \\
\hline
\end{tabular}




\section{Supplementary Table 3}

\begin{tabular}{|c|c|c|c|c|c|c|c|c|}
\hline \multicolumn{7}{|c|}{ Mutation profile of the top 4 more sensitive and resistant cell lines } \\
\hline Gene & NCI-H460 & NCl-H1581 & LOU-H91 & A549 & SK-LU-1 & NCI-H1563 & BEN & NCI-H838 \\
\hline TP53 & NM & $\begin{array}{c}\text { NS } \\
\left(p . Q 144^{*}\right)\end{array}$ & $\begin{array}{c}\text { MS } \\
(p . V 143 M)\end{array}$ & NM & $\begin{array}{c}\text { MS } \\
(p . H 193 R)\end{array}$ & NM & $\begin{array}{c}\text { MS } \\
(p . Y 163 C)\end{array}$ & $\begin{array}{c}\text { NS } \\
\left(p . E 62^{*}\right)\end{array}$ \\
\hline PIK3CA & $\begin{array}{c}\text { MS } \\
(p . E 545 K)\end{array}$ & NM & $\begin{array}{c}\text { MS } \\
(p . E 726 K)\end{array}$ & NM & NM & $\begin{array}{c}\text { MS } \\
(p . E 542 K)\end{array}$ & $\begin{array}{c}\text { MS } \\
(p . G 967 R)\end{array}$ & NM \\
\hline KRAS & $\begin{array}{c}\text { MS } \\
(p . Q 61 H)\end{array}$ & NM & NM & $\begin{array}{c}\text { MS } \\
(p . G 12 S)\end{array}$ & $\begin{array}{c}\text { MS } \\
(p . G 12 D)\end{array}$ & NM & NM & NM \\
\hline STK11 & $\begin{array}{c}\text { NS } \\
\left(p . Q 37^{*}\right)\end{array}$ & NM & NM & $\begin{array}{c}\text { NS } \\
\left(p . Q 37^{*}\right)\end{array}$ & NM & $\begin{array}{c}\text { MS } \\
\text { NS.G242W), }\left(p . Y 272^{*}\right)\end{array}$ & NM & NM \\
\hline
\end{tabular}

$\mathrm{NM}=$ no mutation

$\mathrm{MS}=$ missense

NS = nonsense 


\section{Supplementary Table 4}

\begin{tabular}{|c|c|c|}
\hline \multicolumn{3}{|c|}{ 4-Fold up-regulated genes in resistant } \\
cell lines \\
\hline Genes & logFC & p-value \\
\hline CPE & 5.01 & 0.0033 \\
\hline ACKR3 & 4.13 & 0.0073 \\
\hline GRAMD3 & 3.97 & 0.0003 \\
\hline HCP5 & 3.74 & 0.0289 \\
\hline FOS & 3.47 & 0.0257 \\
\hline NDRG1 & 3.04 & 0.0053 \\
\hline CARD16 & 2.96 & 0.0271 \\
\hline HLA-F & 2.93 & 0.0332 \\
\hline PSMB8-AS1 & 2.82 & 0.0346 \\
\hline ARMCX1 & 2.82 & 0.0389 \\
\hline SATB1 & 2.70 & 0.0231 \\
\hline LNX1 & 2.68 & 0.0350 \\
\hline TMTC1 & 2.60 & 0.0075 \\
\hline MCOLN3 & 2.59 & 0.0035 \\
\hline PLPP3 & 2.57 & 0.0163 \\
\hline TNFRSF21 & 2.57 & 0.0219 \\
\hline PPARGC1A & 2.53 & 0.0493 \\
\hline MSC-AS1 & 2.48 & 0.0466 \\
\hline NLRC5 & 2.43 & 0.0052 \\
\hline TMCC3 & 2.41 & 0.0083 \\
\hline TNFSF10 & 2.37 & 0.0427 \\
\hline UST & 2.36 & 0.0109 \\
\hline DNAJA4 & 2.35 & 0.0491 \\
\hline NMNAT2 & 2.31 & 0.0233 \\
\hline LINC00648 & 2.25 & 0.0112 \\
\hline HLA-J & 2.24 & 0.0250 \\
\hline TAPBPL & 2.24 & 0.0237 \\
\hline TLE2 & 2.21 & 0.0394 \\
\hline ST3GAL6 & 2.14 & 0.0340 \\
\hline AK4 & 2.12 & 0.0500 \\
\hline PRSS21 & 2.08 & 0.0352 \\
\hline NDNF & 2.07 & 0.0487 \\
\hline & 2.05 & 0.0324 \\
\hline
\end{tabular}




\section{Supplementary Table 5}

\begin{tabular}{|c|c|c|}
\hline \multicolumn{3}{|c|}{$\begin{array}{l}\text { 4-Fold down-regulated genes in resistant } \\
\text { cell lines }\end{array}$} \\
\hline Genes & $\log F C$ & p-value \\
\hline SH3KBP1 & -2.11 & 0.0186 \\
\hline C11ORF70 & -2.13 & 0.0329 \\
\hline TGFB2 & -2.15 & 0.0373 \\
\hline ECHDC3 & -2.17 & 0.0144 \\
\hline SLFN11 & -2.22 & 0.0443 \\
\hline HHEX & -2.22 & 0.0003 \\
\hline MTAP & -2.23 & 0.0127 \\
\hline GSAP & -2.24 & 0.0304 \\
\hline FOXF2 & -2.31 & 0.0195 \\
\hline SNHG5 & -2.37 & 0.0004 \\
\hline HIST1H1D & -2.39 & 0.0063 \\
\hline FAM133A & -2.48 & 0.0470 \\
\hline RFLNB & -2.49 & 0.0144 \\
\hline NRXN3 & -2.53 & 0.0223 \\
\hline CEP112 & -2.53 & 0.0404 \\
\hline SMKR1 & -2.55 & 0.0057 \\
\hline P2RX5 & -2.57 & 0.0083 \\
\hline \multirow[t]{2}{*}{ SLC6A8 } & -2.61 & 0.0151 \\
\hline & -2.67 & 0.0055 \\
\hline SEMA3A & -2.84 & 0.0080 \\
\hline GLB1L2 & -3.02 & 0.0031 \\
\hline EEF1A2 & -3.23 & 0.0356 \\
\hline LDOC1 & -3.57 & 0.0231 \\
\hline $\mathrm{CDH} 11$ & -4.39 & 0.0208 \\
\hline VIM & -4.56 & 0.0477 \\
\hline COL5A2 & -5.54 & 0.0120 \\
\hline GJA1 & -7.11 & 0.0001 \\
\hline
\end{tabular}




\section{Supplementary Table 6}

\begin{tabular}{|c|c|}
\hline \multicolumn{2}{|c|}{$\begin{array}{c}\text { Positively correlated genes } \\
\text { with IC50 values }(\mathbf{r}>\mathbf{0 . 5})\end{array}$} \\
\hline Genes & Correlation \\
\hline RNF180 & 0.791 \\
\hline BTD & 0.790 \\
\hline NLRC5 & 0.777 \\
\hline PSMB8-AS1 & 0.766 \\
\hline GVINP1 & 0.759 \\
\hline TAPBPL & 0.754 \\
\hline PPP1R36 & 0.741 \\
\hline HLA-E & 0.738 \\
\hline ATP8A2 & 0.730 \\
\hline SNTB1 & 0.723 \\
\hline FRS2 & 0.722 \\
\hline HLA-J & 0.718 \\
\hline NPY1R & 0.716 \\
\hline LVCAT1 & 0.713 \\
\hline BEND5 & 0.709 \\
\hline RGS4 & 0.707 \\
\hline HLA-F & 0.707 \\
\hline HLA-B & 0.702 \\
\hline MFSD7 & 0.693 \\
\hline PSMB8 & 0.692 \\
\hline STBD1 & 0.692 \\
\hline HCG26 & 0.691 \\
\hline MME & 0.689 \\
\hline LINC01268 & 0.685 \\
\hline HCP5 & 0.684 \\
\hline ACSL5 & 0.683 \\
\hline SH3RF3 & 0.682 \\
\hline fam149a & 0.680 \\
\hline MAB21L2 & 0.676 \\
\hline TG & 0.675 \\
\hline HLA-C & 0.675 \\
\hline BIN1 & 0.672 \\
\hline SLC25A53 & 0.672 \\
\hline RCAN1 & 0.672 \\
\hline CASP1 & 0.671 \\
\hline SERPINA2 & 0.670 \\
\hline NUDT9 & 0.669 \\
\hline
\end{tabular}

\begin{tabular}{|c|l|}
\hline LY96 & 0.658 \\
\hline LINC01082 & 0.657 \\
\hline ETV2 & 0.655 \\
\hline SPTLC3 & 0.649 \\
\hline IFITM10 & 0.648 \\
\hline BTN3A3 & 0.645 \\
\hline B2M & 0.642 \\
\hline BTN3A2 & 0.640 \\
\hline GUCY1A2 & 0.639 \\
\hline HCFC1R1 & 0.636 \\
\hline DPYSL2 & 0.636 \\
\hline GBP1P1 & 0.636 \\
\hline DAO & 0.634 \\
\hline GAS5-AS1 & 0.633 \\
\hline TMEM184C & 0.633 \\
\hline EVC & 0.633 \\
\hline PLPP3 & 0.631 \\
\hline MYL2 & 0.631 \\
\hline PRR32 & 0.628 \\
\hline LOC100507642 & 0.626 \\
\hline PARP3 & 0.622 \\
\hline TMEM229B & 0.618 \\
\hline TRPC3 & 0.618 \\
\hline TPP1 & 0.618 \\
\hline ANXA5 & 0.617 \\
\hline CTSD & 0.617 \\
\hline GPR108 & 0.617 \\
\hline CSF1R & 0.614 \\
\hline ptger3 & 0.613 \\
\hline CDH26 & 0.613 \\
\hline ADAMTS15 & 0.610 \\
\hline CASP3 & 0.607 \\
\hline TMEM99 & 0.605 \\
\hline TBXAS1 & 0.603 \\
\hline ATP10D & 0.603 \\
\hline TCN2 & 0.602 \\
\hline PLA2G1B & 0.602 \\
\hline FLT3LG & 0.602 \\
\hline WRKAG3 & 0.601 \\
\hline nlgn1 & 0.601 \\
\hline & 0.600 \\
\hline
\end{tabular}

\begin{tabular}{|c|l|}
\hline MMAA & 0.599 \\
\hline WIPI1 & 0.599 \\
\hline ZCCHC5 & 0.598 \\
\hline C14orf37 & 0.598 \\
\hline PRDM5 & 0.597 \\
\hline SNX25 & 0.597 \\
\hline MAGEB6 & 0.597 \\
\hline HM13 & 0.596 \\
\hline SSPN & 0.596 \\
\hline RIMS1 & 0.595 \\
\hline LOC100049716 & 0.594 \\
\hline GABRG2 & 0.593 \\
\hline GBP4 & 0.591 \\
\hline JAM2 & 0.590 \\
\hline CFAP52 & 0.589 \\
\hline CCDC130 & 0.588 \\
\hline HLA-DPB1 & 0.588 \\
\hline ZNF75A & 0.587 \\
\hline BMP2K & 0.587 \\
\hline AKAP14 & 0.583 \\
\hline MBNL1-AS1 & 0.583 \\
\hline KCNN2 & 0.582 \\
\hline NTNG2 & 0.582 \\
\hline plxdc2 & 0.582 \\
\hline NAV1 & 0.581 \\
\hline HELQ & 0.581 \\
\hline hla-dqa1 & 0.580 \\
\hline PLSCR4 & 0.579 \\
\hline NOBOX & 0.579 \\
\hline NDN & 0.578 \\
\hline LPXN & 0.577 \\
\hline CRADD & 0.577 \\
\hline CHST2 & 0.576 \\
\hline IFT46 & 0.576 \\
\hline WISP1 & 0.576 \\
\hline CEBPE & 0.574 \\
\hline PIH1D1 & 0.574 \\
\hline MYBPH & 0.573 \\
\hline SHHGEF6 & 0.572 \\
\hline CXCL10 & 0.572 \\
\hline & 0.572 \\
\hline
\end{tabular}




\begin{tabular}{|c|l|}
\hline RRAGB & 0.570 \\
\hline GRN & 0.570 \\
\hline BTBD3 & 0.570 \\
\hline AES & 0.569 \\
\hline UBOX5 & 0.569 \\
\hline BHLHE23 & 0.569 \\
\hline NDST3 & 0.568 \\
\hline COL6A3 & 0.566 \\
\hline IL12RB1 & 0.566 \\
\hline STEAP3 & 0.566 \\
\hline WDFY3 & 0.566 \\
\hline ZBTB47 & 0.565 \\
\hline SURF1 & 0.564 \\
\hline SLC25A4 & 0.564 \\
\hline TraC & 0.563 \\
\hline SP6 & 0.563 \\
\hline CD1D & 0.562 \\
\hline LINC00458 & 0.562 \\
\hline ZNF311 & 0.561 \\
\hline MOK & 0.561 \\
\hline IGFBP5 & 0.560 \\
\hline BEX5 & 0.560 \\
\hline CR1L & 0.559 \\
\hline OLFML2B & 0.559 \\
\hline SHISA3 & 0.558 \\
\hline ZNF629 & 0.557 \\
\hline MTTP & 0.557 \\
\hline TLR3 & 0.557 \\
\hline STX18-AS1 & 0.556 \\
\hline arfip1 & 0.556 \\
\hline LPAR4 & 0.555 \\
\hline hla-a & 0.555 \\
\hline MAPK8IP3 & 0.555 \\
\hline CXCL11 & 0.555 \\
\hline CHMP4B & 0.554 \\
\hline GPR68 & 0.554 \\
\hline NCALD & 0.553 \\
\hline KUNDC3B & 0.552 \\
\hline ADAM21 & 0.552 \\
\hline EMSY & 0.551 \\
\hline
\end{tabular}

\begin{tabular}{|c|c|}
\hline BCL2L1 & 0.550 \\
\hline WEE2-AS1 & 0.550 \\
\hline H2AFV & 0.550 \\
\hline CCRL2 & 0.549 \\
\hline TMEM74B & 0.549 \\
\hline BCAR1 & 0.548 \\
\hline EDNRB & 0.548 \\
\hline COL6A1 & 0.548 \\
\hline LOC440028 & 0.548 \\
\hline CYTH2 & 0.548 \\
\hline ZCCHC18 & 0.547 \\
\hline STX5 & 0.545 \\
\hline LOXL4 & 0.545 \\
\hline OR8B8 & 0.545 \\
\hline MYL5 & 0.543 \\
\hline GRM8 & 0.541 \\
\hline PTN & 0.541 \\
\hline MOCS1 & 0.541 \\
\hline KLF12 & 0.541 \\
\hline cyp2u1 & 0.540 \\
\hline COL1A1 & 0.540 \\
\hline MAP3K7CL & 0.540 \\
\hline SLC15A3 & 0.539 \\
\hline RABAC1 & 0.539 \\
\hline GMPR & 0.539 \\
\hline KDM4B & 0.538 \\
\hline C1QTNF2 & 0.538 \\
\hline $\mathrm{MROH} 8$ & 0.536 \\
\hline CDK15 & 0.536 \\
\hline WNT5B & 0.535 \\
\hline REG1CP & 0.535 \\
\hline TRIM55 & 0.535 \\
\hline hla-dra & 0.534 \\
\hline MSX1 & 0.534 \\
\hline MAP3K11 & 0.534 \\
\hline DNAJB14 & 0.533 \\
\hline STOML1 & 0.533 \\
\hline PLCL1 & 0.533 \\
\hline IQCF4 & 0.533 \\
\hline LOXL1 & 0.532 \\
\hline uba7 & 0.532 \\
\hline SLC2A2 & 0.532 \\
\hline ZFP91 & 0.531 \\
\hline BCAR3 & 0.531 \\
\hline
\end{tabular}

\begin{tabular}{|c|l|}
\hline ZNF215 & 0.531 \\
\hline apol3 & 0.530 \\
\hline C6orf226 & 0.530 \\
\hline LGALS3BP & 0.530 \\
\hline GAS1 & 0.529 \\
\hline MAP4K4 & 0.529 \\
\hline ERC2-IT1 & 0.529 \\
\hline CAGE1 & 0.529 \\
\hline NKX6-1 & 0.528 \\
\hline SLC36A4 & 0.528 \\
\hline LRRC56 & 0.528 \\
\hline CAPN6 & 0.526 \\
\hline SAMD9L & 0.525 \\
\hline SIX2 & 0.525 \\
\hline CWC25 & 0.525 \\
\hline ACY3 & 0.524 \\
\hline TREML3P & 0.524 \\
\hline DIRAS2 & 0.524 \\
\hline MXD4 & 0.522 \\
\hline BTN3A1 & 0.522 \\
\hline CYP8B1 & 0.522 \\
\hline ACVR2A & 0.521 \\
\hline HLA-DRB1 & 0.521 \\
\hline ADAMTSL1 & 0.521 \\
\hline LINC00639 & 0.520 \\
\hline PTX3 & 0.520 \\
\hline TGM2 & 0.519 \\
\hline fam134b & 0.519 \\
\hline MEIS3 & 0.519 \\
\hline CAMK4 & 0.518 \\
\hline zbtb3 & 0.518 \\
\hline TEF & 0.518 \\
\hline CLMP & 0.518 \\
\hline RALGAPB & 0.517 \\
\hline CCDC159 & 0.517 \\
\hline AP5S1 & 0.517 \\
\hline MS4A14 & 0.516 \\
\hline LINC00852 & 0.516 \\
\hline C19orf70 & 0.516 \\
\hline SCARB2 & 0.516 \\
\hline ATBP2 & 0.515 \\
\hline & 0.515 \\
\hline & 0.515 \\
\hline PLXNC1 & 0.515 \\
\hline
\end{tabular}


bioRxiv preprint doi: https://doi.org/10.1101/2021.03.09.434573; this version posted March 9, 2021. The copyright holder for this preprint (which was not certified by peer review) is the author/funder, who has granted bioRxiv a license to display the preprint in perpetuity. It is made available under aCC-BY-NC-ND 4.0 International license.

\begin{tabular}{|c|l|} 
CHRNB2 & 0.514 \\
\hline SNHG11 & 0.513 \\
\hline CNOT6L & 0.513 \\
\hline BDH2 & 0.512 \\
\hline CD74 & 0.512 \\
\hline GFI1 & 0.512 \\
\hline MED16 & 0.512 \\
\hline FAM43A & 0.511 \\
\hline MXD3 & 0.511 \\
\hline ZNF48 & 0.511 \\
\hline GNA11 & 0.510 \\
\hline TLE2 & 0.510 \\
\hline KDM2A & 0.510 \\
\hline ARL9 & 0.509 \\
\hline ABCA5 & 0.509 \\
\hline
\end{tabular}

\begin{tabular}{|c|c|} 
ORMDL3 & 0.508 \\
\hline GAS6 & 0.507 \\
\hline C10orf71 & 0.507 \\
\hline TMUB2 & 0.507 \\
\hline SLC5A12 & 0.506 \\
\hline ITGA10 & 0.506 \\
\hline $\begin{array}{c}\text { EPB41L4A- } \\
\text { AS2 }\end{array}$ & 0.506 \\
\hline SLC39A13 & 0.506 \\
\hline CBLN3 & 0.506 \\
\hline HERPUD1 & 0.505 \\
\hline VEGFB & 0.505 \\
\hline PSMB9 & 0.504 \\
\hline IZUMO4 & 0.504 \\
\hline CUEDC1 & 0.504 \\
\hline
\end{tabular}

\begin{tabular}{|c|c|} 
CFB & 0.504 \\
\hline RNASE11 & 0.503 \\
\hline LINC00969 & 0.503 \\
\hline MCOLN3 & 0.502 \\
\hline MARCO & 0.502 \\
\hline CCDC93 & 0.502 \\
\hline DCTD & 0.501 \\
\hline LRRC66 & 0.501 \\
\hline FIBP & 0.501 \\
\hline KAT5 & 0.501 \\
\hline C10orf113 & 0.501 \\
\hline NMNAT2 & 0.500 \\
\hline LOC283038 & 0.500 \\
\hline PAX5 & 0.500 \\
\hline
\end{tabular}




\section{Supplementary Table 7}

\begin{tabular}{|c|c|}
\hline \multicolumn{2}{|c|}{$\begin{array}{c}\text { Negatively correlated genes } \\
\text { with IC50 values (r<-0.5) }\end{array}$} \\
\hline Genes & Correlation \\
\hline ANKS6 & -0.746 \\
\hline GLRX3 & -0.741 \\
\hline RPL13 & -0.698 \\
\hline FAM206A & -0.683 \\
\hline LYNX1 & -0.672 \\
\hline WBSCR22 & -0.662 \\
\hline LOC440704 & -0.660 \\
\hline CTU2 & -0.659 \\
\hline C10orf76 & -0.657 \\
\hline DUS4L & -0.641 \\
\hline PPA1 & -0.627 \\
\hline FN3K & -0.623 \\
\hline POLA1 & -0.621 \\
\hline EIF3A & -0.615 \\
\hline MRPL43 & -0.615 \\
\hline POLR2A & -0.608 \\
\hline SLC6A8 & -0.604 \\
\hline NKD1 & -0.603 \\
\hline EIF1AX & -0.602 \\
\hline armc9 & -0.598 \\
\hline ZCCHC9 & -0.597 \\
\hline IKBKAP & -0.593 \\
\hline RXFP1 & -0.589 \\
\hline PUDP & -0.589 \\
\hline GBF1 & -0.583 \\
\hline NOLC1 & -0.582 \\
\hline SHH & -0.575 \\
\hline ADPGK & -0.575 \\
\hline DUSP22 & -0.575 \\
\hline HAND1 & -0.571 \\
\hline PGAM5 & -0.571 \\
\hline
\end{tabular}

\begin{tabular}{|c|c|} 
hyal3 & -0.565 \\
\hline HTR1A & -0.564 \\
\hline LINC00544 & -0.564 \\
\hline SLC15A4 & -0.563 \\
\hline LDLRAP1 & -0.563 \\
\hline ANKLE1 & -0.563 \\
\hline RRP9 & -0.562 \\
\hline aire & -0.559 \\
\hline pelp1 & -0.558 \\
\hline COG5 & -0.555 \\
\hline zfp64 & -0.554 \\
\hline RRP12 & -0.553 \\
\hline ACP1 & -0.553 \\
\hline RHBDF2 & -0.552 \\
\hline RIT2 & -0.551 \\
\hline ARMC10 & -0.549 \\
\hline MRGPRG-AS1 & -0.545 \\
\hline SMYD5 & -0.544 \\
\hline EIF2S3 & -0.542 \\
\hline SIGMAR1 & -0.541 \\
\hline USP54 & -0.540 \\
\hline ALDH18A1 & -0.539 \\
\hline NUP93 & -0.539 \\
\hline PDC & -0.539 \\
\hline DHODH & -0.537 \\
\hline HPS6 & -0.536 \\
\hline TCOF1 & -0.536 \\
\hline TNFRSF4 & -0.535 \\
\hline BCCIP & -0.534 \\
\hline TRAV12-1 & -0.533 \\
\hline PES1 & -0.533 \\
\hline HSD17B3 & -0.532 \\
\hline PAPOLB & -0.532 \\
\hline dhx37 & -0.529 \\
\hline & \\
\hline & \\
\hline
\end{tabular}

\begin{tabular}{|c|c|}
\hline NEUROG3 & -0.529 \\
\hline TFB1M & -0.529 \\
\hline SMC1A & -0.527 \\
\hline NME1 & -0.527 \\
\hline RSG1 & -0.527 \\
\hline BLOC1S2 & -0.521 \\
\hline P2RX5 & -0.521 \\
\hline C1QBP & -0.519 \\
\hline ODF1 & -0.518 \\
\hline$t t l l 13 p$ & -0.518 \\
\hline BTNL2 & -0.517 \\
\hline NUP88 & -0.516 \\
\hline MRM1 & -0.515 \\
\hline IQCK & -0.515 \\
\hline pprc1 & -0.514 \\
\hline CD163 & -0.512 \\
\hline IARS & -0.511 \\
\hline rpp25 & -0.510 \\
\hline DDX51 & -0.510 \\
\hline OGFOD1 & -0.510 \\
\hline SLC25A13 & -0.508 \\
\hline ARID1A & -0.507 \\
\hline ZDHHC16 & -0.507 \\
\hline C12ORF10 & -0.507 \\
\hline INPP5A & -0.507 \\
\hline NOC4L & -0.507 \\
\hline LOC100506405 & -0.506 \\
\hline RPL38 & -0.504 \\
\hline CHRNA1 & -0.504 \\
\hline DIMT1 & -0.504 \\
\hline EXOSC1 & -0.503 \\
\hline PDCD11 & -0.501 \\
\hline
\end{tabular}




\section{Supplementary Table 8}

\begin{tabular}{|c|c|}
\hline \multicolumn{2}{|c|}{ Top 20 genes in CRISPR/Cas9 screening } \\
\hline Gene & Pos-score \\
\hline COX5B & 0.000016396 \\
\hline MARK4 & 0.000025227 \\
\hline TATDN3 & 0.000030289 \\
\hline CTAGE1 & 0.000040364 \\
\hline CBR1 & 0.000044941 \\
\hline hsa-mir-365a & 0.000051036 \\
\hline TMC8 & 0.000056552 \\
\hline hsa-mir-138-1 & 0.000066093 \\
\hline SLC25A52 & 0.000070277 \\
\hline CCDC106 & 0.000075681 \\
\hline STK39 & 0.000077296 \\
\hline hsa-mir-181d & 0.000096834 \\
\hline hsa-mir-6856 & 0.00011253 \\
\hline hsa-mir-7850 & 0.00011772 \\
\hline LIPG & 0.00012613 \\
\hline hsa-mir-6730 & 0.00015096 \\
\hline hsa-mir-1184-3 & 0.00015597 \\
\hline hsa-mir-548f-5 & 0.00018152 \\
\hline ACSL5 & 0.00020533 \\
\hline PDE2A & 0.00021423 \\
\hline
\end{tabular}

